\title{
Destabilizing Effects of Ionizing Radiation on Chromosomes: Sizing up the Damage
}

\author{
Michael N. Cornforth ${ }^{a}$ Joel S. Bedford ${ }^{b}$ Susan M. Bailey ${ }^{b}$ \\ aDepartment of Radiation Oncology, University of Texas Medical Branch, Galveston, TX, USA; \\ ${ }^{b}$ Department of Environmental \& Radiological Health Sciences, Colorado State University, Fort Collins, CO, USA
}

\section{Keywords}

Chromosome aberrations · lonizing radiation · Mutations ·

$\mathrm{dGH} \cdot$ Inversions · DNA sequencing

\begin{abstract}
For long-term survival and evolution, all organisms have depended on a delicate balance between processes involved in maintaining stability of their genomes and opposing processes that lead toward destabilization. At the level of mammalian somatic cells in renewal tissues, events or conditions that can tip this balance toward instability have attracted special interest in connection with carcinogenesis. Mutations affecting DNA (and its subsequent repair) would, of course, be a major consideration here. These may occur spontaneously through endogenous cellular processes or as a result of exposure to mutagenic environmental agents. It is in this context that we discuss the rather unique destabilizing effects of ionizing radiation (IR) in terms of its ability to cause large-scale structural rearrangements to the genome. We present arguments supporting the conclusion that these and other important effects of IR originate largely from microscopically visible chromosome aberrations.
\end{abstract}

(c) 2021 S. Karger AG, Basel

\section{Introduction}

All exogenous agents capable of producing chromosome aberrations (CAs), i.e., clastogens, are mutagens, and most are also carcinogens. For that reason, cytogenetic damage has long been a favored surrogate endpoint for assessment of carcinogenic and mutagenic potential. As we outline below, one very important conclusion from ionizing radiation (IR) mutagenesis studies in cells of higher eukaryotic organisms has been that large-scale genomic structural changes generally dominate the spectrum of new mutations, as compared with point mutations or other small intragenic changes. We will summarize here several lines of evidence supporting this conclusion. Granted, the spectrum of mutations can differ vastly, depending on the mutagenic agent, but here our emphasis will be on mutagenic events resulting from large-scale structural changes to the mammalian genome caused by IR. These include deletions, insertions, inversions, and translocations, any of which can disrupt genes, alter the control of gene expression, or even result in expression of new fusion sequences. IR is virtually unique regarding its efficiency for producing prompt DNA double-strand breaks (DSBs) randomly throughout the ge-

\footnotetext{
Karger"
}

Correspondence to:

Susan M. Bailey, susan.bailey@ colostate.edu 
nome, which is the prerequisite lesion for the development of these structural rearrangements.

To the extent that chromosomal aberrations underlie the important biological effects of IR, it follows that studies relating to their formation and detection are central to understanding mechanisms of radiation action. Here, particular focus is given to advances in methodologies that have enabled the detection of CAs previously considered as "cryptic" and to discuss some far-reaching implications regarding our ability to fully account for them.

\section{Background}

\section{Radiation Effects, Chromosomal Aberrations, and DNA Double-Strand Breaks}

Heritable changes among those cells that survive IR exposure underlie some of the most important biological effects of IR. As we argue in subsequent sections, these effects in higher eukaryotes are due largely to CAs that result from the misrejoining of DSBs. Considerations based on micro-dosimetry and free radical chemistry lead to the conclusion that ion clusters along single charged particle tracks - fast electrons in the case of X- and gamma-rays - are responsible for the production of DSBs [Kellerer and Hug, 1972; Goodhead, 1989; Ward, 1990], which are the precursor lesions for CA formation. In other words, DSBs do not arise from the close proximity of 2 coincident single-strand breaks (SSBs), each produced independently on opposite strands of a DNA molecule by multiple independent tracks in close proximity.

\section{Spectra of IR-Induced Aberrations}

IR produces many different types and subtypes of chromosomal aberrations as viewed during the first mitosis after exposure [Sax, 1940; Lea, 1946; Savage, 1976]. By conventional or classical radiation cytogenetics terminology, chromosome-type aberrations are seen at the first post-irradiation mitosis after irradiation of cells in G1 or G0, before DNA replication and chromosome duplication occurs. For these, the regional location of breakpoints along the aberrant chromosome(s) is the same on both chromatids because the newly formed structural abnormality in the G1/G0 chromosome is replicated during S-phase, and therefore is seen on both chromatids of the mitotic chromosome at precisely the same location (Fig. 1a). The other main class of aberrations are the chromatid-types. These are seen in cells irradiated during G2 phase, or in $\mathrm{S}$ phase at locations after replication has occurred, so the abnormality involves the damaged chro-

Radiation Damage to Chromosomes matid only while the sister chromatid remains unaffected (Fig. 1b). Aside from a small handful of chemical agents that produce prompt DSBs in DNA, this cell-cycle dependence of aberration type (chromosome- vs. chromatidtype) is virtually unique to IR. Agents that do not produce prompt DSBs, but produce lesions such as SSBs, base damage, bulky adducts, or DNA crosslinks result in the appearance of only chromatid-type aberrations after G1 treatment and progression to mitosis [Bender et al., 1974]. In a later section we discuss chromatid-type exchanges in the context of DNA repair mechanisms where they become important. For now, we forego a detailed discussion of them mainly because most of what is said about chromosome-type aberrations applies to them as well.

Decades of biophysically grounded research supports the near-universal viewpoint that exchange aberrations arise from misrejoining among radiogenically broken ends of 2 or more DSBs in close proximity [Cornforth, 2006]. This view is further strengthened by studies directly confirming Mueller's and McClintock's original observations that the natural ends of chromosomes are protected from rejoining mischief; specifically, functional telomeres do not rejoin with IR-induced DSBs [Cornforth et al., 1989]. Yet when telomeres become dysfunctional via loss of their critical end-capping function - thus appearing to the cell as a DSB - IR-induced DSBs and now-uncapped telomeres are able to freely rejoin with one another [Bailey et al., 2004a; Bailey and Cornforth, 2007]. Terminal deletions (i.e., breaks that simply fail to rejoin) do not involve an exchange event, but these represent a relatively small fraction of the total radiation-induced aberrations [Loucas and Cornforth, 2001]. Chromosome-type exchanges occur between or among different chromosomes (interchanges), or within the same chromosome (intrachanges). Further, interchanges (translocations) may be symmetrical (balanced), with each product retaining a centromere, or asymmetrical (unbalanced), in which an acentric fragment is always produced during formation; for example, a "dicentric" is composed of the dicentric element itself, together with an associated compound acentric fragment. The term "compound" denotes the fact that the fragment is also a product of rejoining; in this example, the fusion of 2 acentric fragments produced from each broken end of the 2 chromosomes involved (Fig. 1a).

Likewise, intrachanges that occur within a given chromosome, may be either symmetrical or asymmetrical (Fig. 2). The symmetricals, commonly called inversions, include inter-arm types where the centromere lies within the inverted region (pericentric inversions), and intraarm types that do not include the centromere (paracen- 
Fig. 1. a Simple reciprocal chromosometype interchanges occur in G1/G0 phases of the cell cycle. They can be resolved symmetrically to produce translocations, or asymmetrically to produce dicentrics and associated compound acentric fragments. b Chromatid-type aberrations occur in S/ G2 phases of the cell cycle. Both symmetrical and asymmetrical resolutions produce cruciform structures (quadriradials) at metaphase. The asymmetrical U-types and the symmetrical X-types are distinguishable on the basis of the relative position of the 2 centromeres.
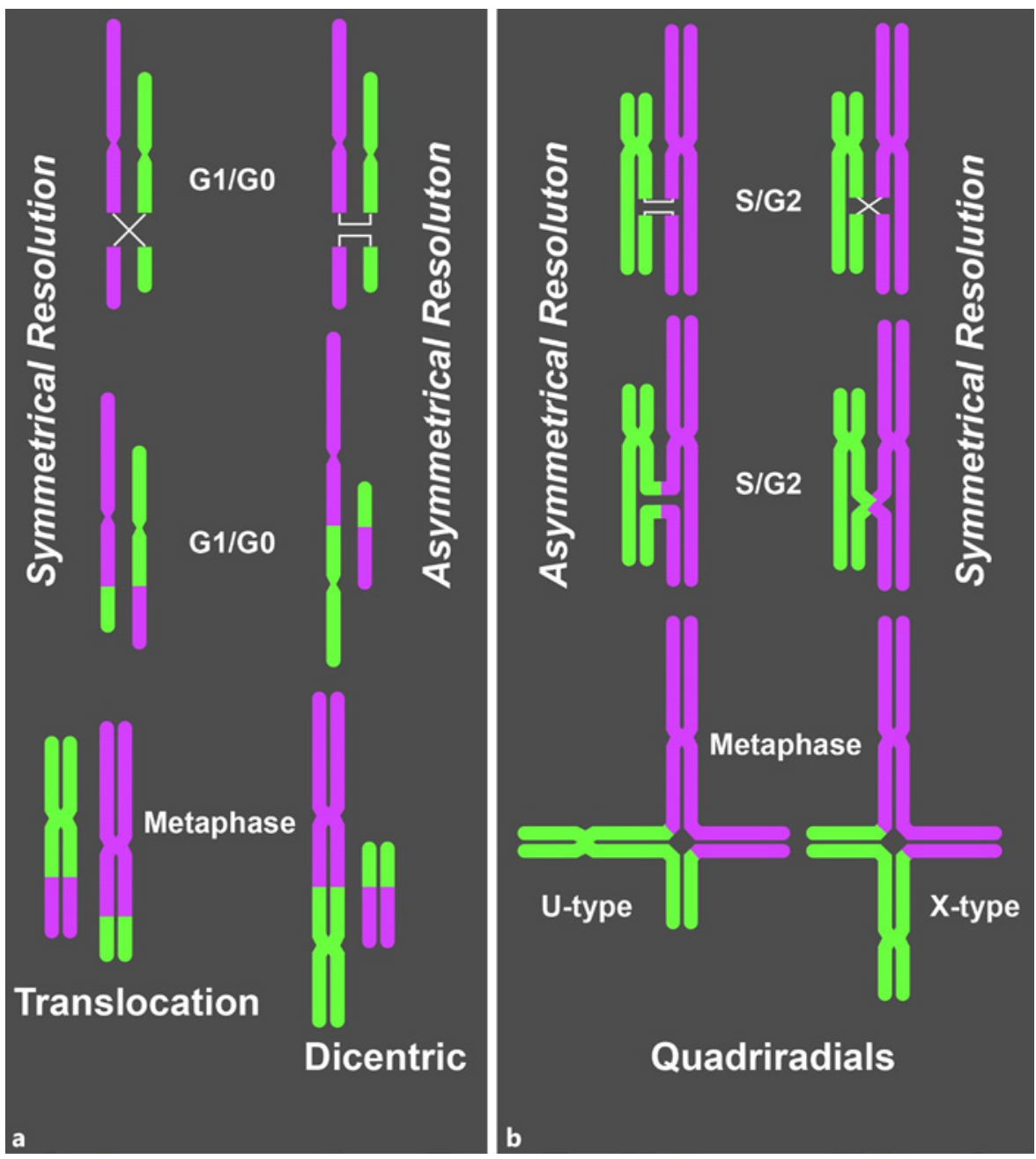

tric inversions). The asymmetrical intrachanges include inter-arm types, where a centric ring and an associated compound acentric fragment are formed, and intra-arm types that result in formation of an acentric ring fragment and a (shortened) chromosome that no longer contains the deleted region previously occupied by the ejected ring fragment. Small acentric rings of this type are commonly referred to as interstitial deletions (IDs). Being fundamentally ring-type structures, they are not to be confused with terminal deletions, discussed below.

For normal diploid cells irradiated in G1/G0, mostly all microscopically visible asymmetrical exchanges are lethal to the cells bearing them because of genetic deficiencies associated with loss of the acentric fragment(s) in all cell progeny [Bedford et al., 1978; Revell, 1983]. These asymmetrical exchanges are relatively easy to detect following solid histological staining (e.g., Giemsa), although it is usually not possible to accurately identify the particu- lar chromosomes from which they derive. Symmetrical chromosome-type exchanges are difficult to detect in somatic cells by solid staining, but are clearly seen for chromatid-types and in meiotic cells due to configurations generated by pairing of homologous regions. Newer and more powerful techniques discussed below have since substantiated the oft-assumed notion that symmetrical and asymmetrical counterparts of any exchange product occur with nearly equal frequency [Loucas et al., 2013].

\section{Uncovering Cryptic Aberrations}

For many years, much of the work in human radiation cytogenetics involved the study of chromosome-type asymmetrical exchanges, such as dicentrics, centric and acentric rings, and IDs. These are easily identified and quantified with great accuracy using opaque histological 
stains like aceto-orcein and Giemsa, while their symmetrical counterparts remained "cryptic." In the 1970s, various forms of chromosome banding techniques were developed that employed fluorescent DNA-binding dyes like quinacrine derivatives [Caspersson et al., 1972], partial proteolytic digestion using enzymes like trypsin [Seabright, 1971], or hypertonic thermal denaturation [Dutrillaux and Lejeune, 1971]. The resulting respective Q-, G-, or R-bands produced distinct and reproducible longitudinal banding patterns along the length of a given chromosome that allowed for the visualization of symmetrical interchanges like reciprocal translocations between different chromosomes. Relatively large inversions resulting in obvious changes in banding patterns were also resolvable by these methods [Dutrillaux et al., 1986].

Equally important was the fact that the breakpoint junctions of symmetrical exchanges themselves could now be mapped to specific chromosome and band locations in the genome. While mapping breakpoints by banding is still practiced, it is quite crude by molecular standards, mainly because the bands themselves are relatively large, on the order of 5 DNA megabases, depending on the banding method used and the state of chromosome condensation [Bickmore, 2001]. It is often unappreciated that the rather precise breakpoint assignments reported in the clinical cytogenetic literature benefit from the fact that the subject material (i.e., proband) typically contains cells with the same recurrent translocation or inversion, meaning that an overall consensus of breakpoint locations is possible. For the examination of a population of cells exposed to some genotoxic agent, this is rarely the case since each affected cell will contain its own unique constellation of chromosomal rearrangements. In practice, breakpoint localization by banding is even worse because of problems inherent to pattern recognition that limit accuracy to within 3 bands [Savage, 1977].

\section{Fluorescence in situ Hybridization}

Modern fluorescence in situ hybridization (FISH) techniques have improved the situation considerably [Pinkel et al., 1986]. With the advent of whole chromosome "painting" (WCP) essentially all interchanges involving painted chromosomes are detected, irrespective of breakpoint location, and translocation analysis can be conducted on a cell-by-cell basis with remarkable alacrity. Although chromosome painting does little or nothing to improve breakpoint localization within chromosomes, it has nevertheless completely revolutionized the way we view chromosomal interchanges produced by IR. It soon became evident that many of the translocations and dicen-

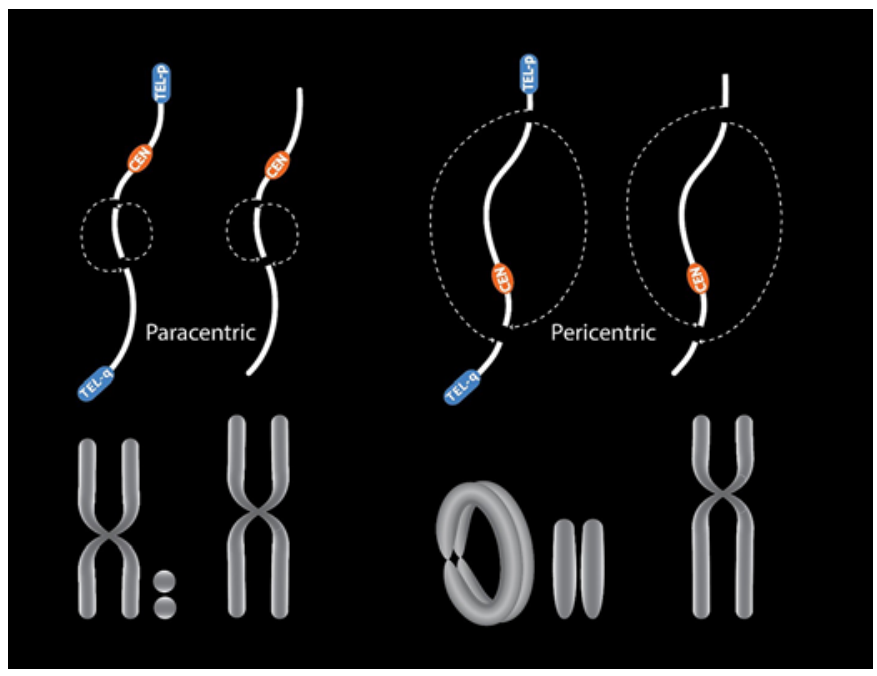

Fig. 2. Resolution of break pairs during the formation of chromosome-type intrachanges during G1/G0 and their appearance at metaphase using solid histological stains (e.g., Giemsa). The asymmetrical forms produce ring-type fragments. The symmetrical forms yield inversions. Left The 2 breakpoints are both situated on one chromosome arm (paracentric). The asymmetrical resolution produces an acentric ring structure (e.g., interstitial deletion) and a shortened centric fragment which, depending on the size of the deleted ring fragment, can lead to detectable changes in morphology (i.e., altered p:q arm ratios). The symmetrical resolution leads to an inversion, which is undetectable by solid staining, but if large enough, can be detected by various banding techniques. Right The 2 breakpoints straddle the centromere (pericentric). In the case of asymmetrical resolution, a centric ring and compound acentric fragment are produced. Symmetrical resolution leads to an inversion that can often be detected as an altered p:q arm ratio.

trics previously assumed to be simple reciprocal events when using solid staining, were nothing of the sort [Sabatier et al., 1987; Brown and Kovacs, 1993]. Hybridization patterns produced by WCP of 1, 2, or 3 individually painted chromosomes forced the conclusion that a significant fraction of exchanges previously assumed to be simple reciprocal events involving 2 chromosomes were actually complex exchanges involving 3 (and often more) chromosomes. The advent of full 24-color combinatorial chromosome painting, such as mFISH [Speicher et al., 1996], further cemented this concept, and it is now well-appreciated that IR-induced exchange aberrations can be exceedingly complex, involving several chromosomes and breakpoints [Cornforth, 2001; Loucas and Cornforth, 2001]. Things were more cryptic than we had previously even imagined.

Unfortunately, neither WCP nor mFISH is capable of detecting intrachromosomal inversions; especially the small paracentrics, since they usually do not significantly change chromosome morphology (e.g., arm ratios; Fig. 2). 
Other FISH-based methodologies employ small punctate multi-fluor "site-specific" double-stranded oligomere probes that can be made to target virtually any portion of the genome, and these have been used to great effect in interphase mapping the fine structure of a variety of chromosomal rearrangements, such as translocations [Lee et al., 1993] and inversions [Mancini et al., 1995]. The downside is that design of such probes for this purpose requires reasonably detailed prior knowledge of breakpoint locations. For that reason, the approach has little practical value in assessing genome-wide damage to an irradiated cell population.

There are a number of reasons why the study of inversions deserves special attention. Being symmetrical exchanges, they retain their attachment to the spindle apparatus, allowing their orderly segregation to daughter cells during cell division. Thus, they are not lethal, unless the breakpoints themselves disrupt vital gene sequences or important regulatory elements. The highly transmissible nature of inversions makes them potential sources of heritable IR-induced mutations, to include driver mutations associated with carcinogenesis. We will return to this point in later sections.

\section{Cytogenomics-Based Approaches}

Development of directional genomic hybridization (dGH) can trace its origins to the demonstration by Taylor and colleagues [Taylor et al., 1957; Taylor, 1958], that semiconservative replication of DNA was reflected cytogenetically by autoradiographic labeling patterns produced in sister chromatids at the first and second mitosis following incorporation of tritiated thymidine, a result published just prior to the demonstration of semiconservative DNA replication by Meselson and Stahl [1958]. These seminal studies provided evidence that chromosomes are comprised of a single contiguous DNA molecule from one end of the chromosome to the other and demonstrated the phenomenon of sister chromatid exchange (SCE). Higher resolution measurements followed, employing labeling schemes based on the incorporation of nucleotide analogs, principally bromodeoxyuridine (BrdU) [Perry and Wolff, 1974; Latt, 1978]. Alternations of the basic approach were later used for the identification of inversions resulting from IR exposure, which showed that IDs and inversions (their symmetrical counterpart) were produced with roughly equal frequencies [Muhlmann-Diaz and Bedford, 1995]. Unfortunately, this latter approach was limited to detecting de novo inversions in cells arriving at their first mitosis after irradiation, meaning that pre-existing inversions were not detectable.

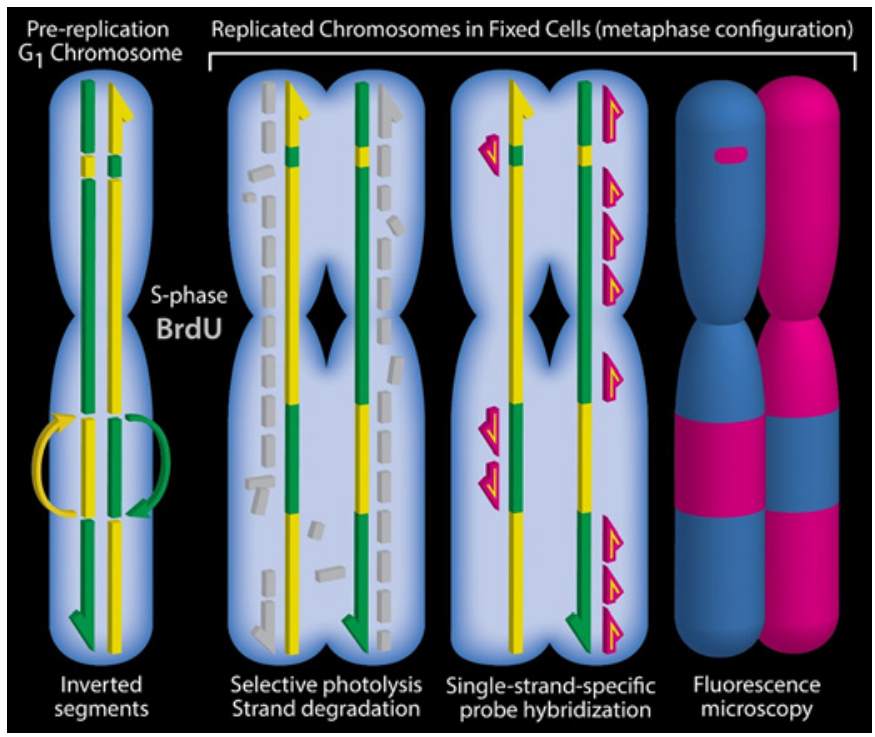

Fig. 3. The principles of dGH. Following S-phase, each complementary polynucleotide strand from a G1 chromosome segregates into respective sister chromatids at metaphase. When BrdU is incorporated during DNA synthesis, each nascent strand becomes photo-labile, allowing it to be selectively degraded. For the purposes of in situ hybridization, this results in a metaphase chromosome whose sister chromatids are single-stranded and complementary. Because inverted DNA sequences must reverse their $5^{\prime} \rightarrow 3^{\prime}$ orientation in order to preserve polarity, individual strands within the inversion are obligated to "switch places" between the sister chromatids; therefore, hybridization of fluorescently tagged directional complementary single-stranded probes to unique sequences along either chromatid results in a microscopically visible signal that "switches" from one chromatid to its sister. For large inversions, the signal switch is accompanied by a corresponding lack of signal on the opposite chromatid; for small inversions the unlabeled segment is often obscured by the brightness of the fluorescent signal. Reproduced from Ray et al. [2013].

The next advance in inversion discovery came with development of the strand-specific methodology of Chromosome Orientation FISH (CO-FISH), an approach that purposely restricted hybridization of synthetic directionally oriented single-stranded probes to only one sister chromatid of a metaphase chromosome [Goodwin and Meyne, 1993; Meyne and Goodwin, 1995]. Initially, COFISH was confined to probing repetitive regions of the genome for which synthetic directional oligos were conveniently constructed, specifically centromeres and telomeres [Bailey et al., 1996a, b, 2004b; Williams et al., 2011]. Continued refinement of the human genome database and bioinformatics design strategies freed CO-FISH from these constraints, as it enabled the synthesis of directionally oriented ( $5^{\prime}$ pter $\rightarrow 3^{\prime}$ qter) single-stranded probes tar- 


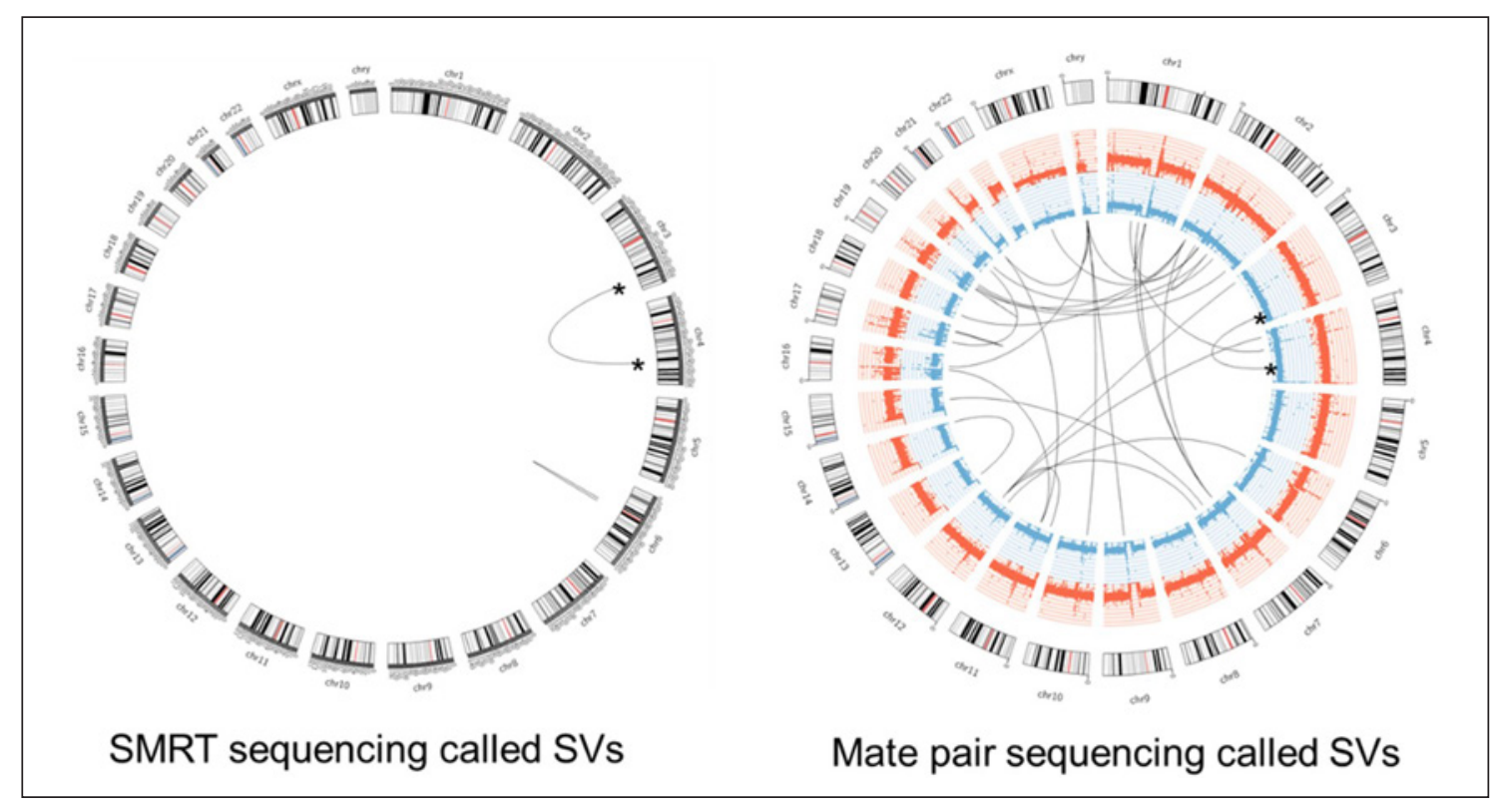

Fig. 4. Circos diagram showing structural variant (SV) calls to the human reference genome by massively parallel sequencing for clone K1-400C4 whose progenitor cell was exposed to gammarays. Left Single-molecule/real-time sequencing (SMRT). Right Mate pair sequencing. Putative breakpoints of SVs are shown for both methods. Asterisks indicate SVs with cytogenetic support by
mFISH. Note the large number of calls made to the reference genome by mate pair sequencing that do not appear following SMRT sequencing, most of which are false-positive calls. SMRT correctly identified the $\mathrm{t}(3 ; 4)$ translocation in this mutant clone. Unpublished, courtesy of Dr. Ralf Kittler. geting unique complementary sequences along the length of any given chromosome. By synthesizing and pooling many such oligos it became possible to effectively "paint" entire individual chromatids, thus making even small inversions readily visible, which appear as a "double-switch" in the single-sided hybridization pattern from one chromatid to its sister [Ray et al., 2013, 2014; Robinson et al., 2019] (Fig. 3).

\section{Massively Parallel Sequencing}

In principle, $\mathrm{dGH}$ is capable of detecting inversions as small as $\sim 30 \mathrm{~kb}$ [Ray et al., 2013]. But for basepair-level resolution, some form of genome sequencing is required. Inroads into mammalian genomic sequencing were first made via the rather tedious approach of "chromosome walking" [Nakaseko et al., 1986]. This was superseded by various methodologies making use of massively parallel sequencing (MPS) in concert with information provided by the Human Genome Initiative. MPS falls into either short-read or long-read categories. The first of these utilizes short DNA sequence information in order to reassemble longer end-to-end contiguous regions (contigs). It includes paired-end sequencing [Korbel et al., 2007; Bashir et al., 2008], whereby both ends of short DNA frag- ments (typically $<500 \mathrm{bp}$ ) are sequenced, and the resulting paired-end reads are then mapped to a reference genome assembly, such as that provided by the latest build assembly from the Human Genome Project (https:// www.ncbi.nlm.nih.gov/assembly/GCF_000001405.39). As a case example, if a read from one end of a fragment indicates its location to be on chromosome 3 , while the other end of the same fragment maps to chromosome 4 , then a reciprocal $t(3 ; 4)$ translocation is provisionally indicated. Normally such analysis would be followed by conventional Sanger sequencing for confirmation.

The inherent weakness in this approach is that the relatively short reads (75-300 bp, most commonly 150 bp) of paired-end libraries (containing fragments spanning the breakpoints of interest) are also likely to include various DNA repeat sequences, which are known to be ubiquitously scattered throughout mammalian genomes [de Koning et al., 2011]. In terms of locating exchange-aberration breakpoints, this leads to a large number of "false-positive" calls to the reference genome. The situation is substantially improved through the long-insert/short-read techniques like mate-pair sequencing [Vergult et al., 2014], whose libraries consist of fragments up to $5 \mathrm{~kb}$ in length, thereby increasing the 
chances that coverage will extend beyond the bounds of problematic repeat regions.

While short-read methods like paired-end and matepair sequencing remain useful for many applications, we imagine that alternative long-read approaches will eventually become the norm for analysis of IR-induced chromosomal rearrangements. Examples include single-molecule/real-time sequencing (SMRT) developed by Pacific Biosciences [Ardui et al., 2018], which is capable of directly reading sequence information from large-sized (15-30 kb) fragments (Fig. 4). An additional benefit to this technology is its ability to detect concurrently small basepair changes as well, although, as with the short-read approaches, confirmatory Sanger sequencing is likely necessary. Currently, the costs associated with certain MPS technologies, particularly SMRT, may be prohibitive in some experimental settings. But as prices for these services continue to fall, and the methodologies continue to evolve, we see next-generation sequencing as playing an increasingly important role in the detection and characterization of large-scale structural variants like translocations and inversions [Behjati et al., 2016; Nilsson et al., 2017]. One can reasonably expect many more discoveries of IR-induced "cryptic" rearrangements to follow.

\section{Implications}

What follows is a discussion of how use of the methods described above has impacted - or is likely to impact in the near future - our basic understanding of radiation effects in mammalian cells.

\section{Complex Interchanges and Dose Response}

Until mFISH became part of the cytogeneticist's arsenal of investigative tools, few investigators realized just how frequent IR-induced complex aberrations (CXAs) really were [Testard et al., 1997]. For high LET radiations, like alpha particles or heavy ions, they always represent a large fraction of the total aberration yields. For low LET IR, their relative abundance (compared to simple CAs) is strongly dose-dependent. For that reason, it is not uncommon practice for investigators to ignore their presence for doses below about 2 Gy of X- or gamma-rays. While in some cases this practice may be reasonably justified; often it is not.

One of the simplest CXAs one encounters following IR exposure requires the misrejoining of 3 radiogenic breaks partitioned among 3 different chromosomes. However, it is not rare to find CXAs involving 4, 5, 6 (or more) chro- mosomes, each of which requiring (minimally) an equal number of radiogenic breaks for their formation. Intuitively, it seems illogical to ascribe equal levels of damage for a CXA involving 3 chromosomes, compared to that of a CXA involving 5 chromosomes; the latter clearly representing a higher-level of damage. With this in mind, it seems reasonable to examine dose-response relationships based on the total number of requisite breakpoints, rather than by the mere presence or absence of a particular simple or complex exchange event [Loucas and Cornforth, 2001; Cornforth and Loucas, 2019]. By this measure, gamma-ray-induced complex exchange breakpoints actually exceed the breakpoints of simple exchanges for doses above about $5 \mathrm{~Gy}$.

A central tenet of radiation cytogenetics is that the upward curvature typical of dose responses for CAs in response to low LET exposures is due to the requisite pair of radiogenic breaks (e.g., on different chromosomes) being formed by independent charged particle tracks [Neary, 1965a] - in this case fast electrons from photoabsorptive events. Prior to WCP and mFISH, when solid histological stains were the norm, this neatly explained the dose response for aberrations like dicentrics, virtually all of which were assumed to be simple asymmetrical exchanges. It therefore came as somewhat of a shock when Simpson and Savage [1996], using single-chromosome WCP, reasoned that the dose response for true simple exchanges must be approximately linear with dose. Nevertheless, the prediction of scant curvature for simple exchanges was later substantiated by direct experimental evidence gathered using mFISH [Loucas et al., 2013]. In other words, most of the visible curvature seen in the CA dose response following low LET exposure is due to complex exchanges! The explanation given for the approximate linearity of simple-exchange dose responses stems from the realization that simple exchanges do not form in isolation, meaning that the exact same break-rejoining processes destined to form complex exchanges are in constant competition for radiogenic breaks that, left alone, would otherwise be destined to form simple exchanges. In a similar fashion, 5-way CXAs effectively "steal away" breaks that might otherwise be destined to form 4-way CXAs. Likewise, the 4-ways steal breaks from the 3-ways, and so on, leaving formation of simple reciprocal 2-way exchanges to fight off several thieves, thus causing them to lose much of their upward curvature [Loucas et al., 2004], a notion further supported by recent modeling studies [Shuryak et al., 2004].

We believe the full extent of these findings is largely unappreciated with respect to their impact on fundamen- 
tal theories of radiation action. To understand this requires a brief description of the venerable linear-quadratic model, whose origins began in the 1940s [Lea, 1946] and which has been discussed on many subsequent occasions since [Neary, 1965b]. Although not specifying chromosome exchanges in particular as the lesion underlying biological effects, the Theory of Dual Radiation Action provides its formal mathematical underpinnings [Wolff, 1963; Kellerer and Rossi, 1972]. These ideas have been used to describe a wide range of radiobiological phenomena, serving as the cornerstone of radiation biology for more than half a century. When applied to the production of CAs (Y) as function of dose (D), this biophysical model is described by a the second-order polynomial $\mathrm{Y}=$ $\alpha \mathrm{D}+\beta \mathrm{D}^{2}$. It makes the crucial assumptions that formation of a chromosome exchange requires a pair of radiogenic breaks, and that these break-pairs can derive from one of 2 sources. For cytogenetics, the linear term represents CAs produced by the passage of single charged particle track, while the dose-squared term represents CAs that require the coincident passage of 2 independent tracks. The model further assumes that individual breaks destined to rejoin (or misrejoin) with each other must be proximate, meaning close in both time and space. Importantly, it is this second $\beta \mathrm{D}^{2}$ term that is responsible for the characteristic upward curvature in the dose-response curve with increasing dose for low LET radiation, and for all dose-rate effects due to break rejoining during the course of exposures.

In light of the preceding discussion on complex exchanges, the interpretation of this dose-squared term requires some serious rethinking, or at the very least, the adoption of a more nuanced view. Rather than the $\beta \mathrm{D}^{2}$ term representing lesion-interaction between just 2 radiogenic breaks, each produced by a separate and independent track, we are now forced to view it as an exceedingly complex interactive term that encompasses rejoinings among multiple breakpoints on multiple chromosomes, all in competition with one another. In that sense, the biophysical meaning of the $\beta \mathrm{D}^{2}$ term is an oversimplification that coincidentally approximates a more complex process leading to the observed curvature in the dose response for acute exposures. Stated another way, it is hard to avoid concluding that while the $\alpha \mathrm{D}$ term retains harmony and concrete meaning in relation to the linear quadratic model, the classical biophysical interpretation of the $\beta \mathrm{D}^{2}$ term no longer retains such tangible meaning.

To understand the biophysical mechanisms underlying the formation of both simple and complex aberra- tions, it is worth recalling J. Savage's reminder that broken ends of chromosomes are not free to "flap about" within the nucleus to randomly encounter potential exchange partners [Savage, 2000]. The structural and functional organization of chromatin within the nucleus along with various other factors surely can restrict or facilitate participation of breaks in the process of exchange formation [Bailey and Bedford, 2006]. At one end of the organizational spectrum are reports demonstrating microtubule-mediated movement of DNA DSB ends during the process of nonhomologous end-joining (NHEJ) [Lottersberger et al., 2015]. At the other end of this spectrum lie many unanswered questions concerning IR-induced CAs. These stem from the fact that individual chromosomes in the interphase nucleus are not as diffuse as once commonly believed. Instead, they occupy rather distinct (and surprisingly compact) domains or "territories" that are easily seen following whole-chromosome FISH. Various models have been developed to accommodate these and other features of interphase architecture [Lichter et al., 1988; Cremer et al., 2000; Cremer and Cremer, 2001; Edelmann et al., 2001; Friedland et al., 2008].

For simple pairwise reciprocal interchanges it is not difficult to imagine break rejoining taking place across a shared boundary between 2 such interphase domains, and similar considerations have been applied to the production of exchanges following exposure to high LET alpha particles [Anderson et al., 2001, 2002]. But what about complex exchanges whose formation requires 4,5 (or even more) breaks on different chromosomes - each with the requirement that their broken ends freely and independently assort during exchange formation [Cornforth, 2001]? How is it even possible for several interphase domains to share a common boundary (of any significant dimension) in 3-dimensional space? Another issue affecting the likelihood of exchange formation pertains to the arrangement among specific chromosomes during interphase. Numerous reports support the idea that such an arrangement is not random, and that certain territorial domains more closely associate with one another. This, for the implied purpose of bringing together certain loci [Croft et al., 1999; Boyle et al., 2001], and thus effecting gene regulation [Cremer and Cremer, 2001]. In such a case, randomly induced DSBs following exposure to low LET IR ought to produce an excess of exchanges between those chromosomes whose interphase domains are preferentially close to one another - i.e., "hotspot clusters" in the distribution. However, while an analysis of some 1,900 mFISH karyotypes from X- and gamma-irradiated lymphocytes did, in fact, provide some evidence of clus- 
tering, the effect was superimposed on a dominant pattern of spatial randomness [Cornforth et al., 2002b]. These results, however, should be viewed in the context of studies suggesting nonrandom arrangements which when, and if they occur - are probably dependent on cell type and stage of differentiation [Neves et al., 1999].

Before leaving the topic of complex exchanges, it is important to point out that their unexpectedly high frequency does not argue against the proposition that dose-rate and dose-fractionation effects still involve a fundamental time-dependent factor based on the pairwise rejoining and misrejoining among chromosome breaks. For independently produced breaks, a minimum of 2 (and often more) breaks are necessary to produce an exchange by misrejoining of the broken ends. Nevertheless, the rejoining or misrejoining of breaks still occurs in a pair-wise fashion. And since the initial radiogenic breaks can rejoin and disappear with time, there will be fewer potentially interacting clusters of 2 or more of these. Consequently, fewer exchanges of any degree of complexity can be produced per unit total dose when the dose is spread over time, as it is for reduced dose-rate or time-fractionated exposures.

The lower limit of this effect - where further reduction in dose-rate does not further reduce the effect per unit dose due to disappearing breaks - is determined by the single-track exchanges that represent the dose-rate-independent $\alpha \mathrm{D}$ term. The upper dose-rate limit is achieved when the rate of production of independent breaks is so high relative to their rejoining rate that there is negligible difference in the number of such breaks present contemporaneously for a given dose with further increases in dose rate. A break rejoining rate corresponding to halftimes of around $1-2 \mathrm{~h}$, leads to a dose rate effect operating over a range between about 0.3 and $60 \mathrm{~Gy} / \mathrm{h}$ for cell killing [Wells and Bedford, 1983]. Peng et al. [2012] noted that a remarkably similar maximal dose rate effectiveness factor of about 3-fold has been observed over this same span of doses for biological effects ranging from somatic mutations in Tradescantia [Nauman et al., 1975] to specific locus mutations in mouse spermatogonia [Russell et al., 1958; Russell and Kelly, 1982; Russell and Hunsicker, 2012], and chromosomal aberrations in human cells (Fig. 5) [Cornforth et al., 2002a]. The simplest explanation for these congruent observations is that they all share a similar mechanism to that underlying the formation of chromosome aberrations. Of course, processes other than DNA break rejoining/misrejoining may also come into play to alter dose-rate effectiveness factors, such as a change in the radiosensitivity of the system during prolonged exposures [Mitchell et al., 1979].

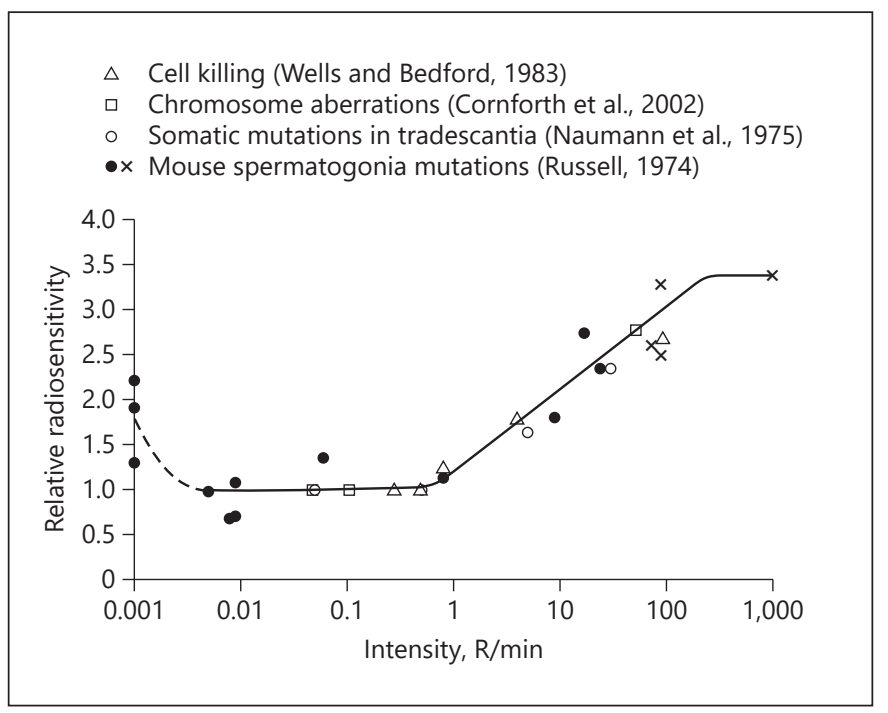

Fig. 5. Relative radiosensitivities for various damage end points measured in a variety of biological systems as indicated, as a function of X- or gamma-ray exposure/dose rates. The effect per unit dose observed at a given dose rate was divided by the effect per unit dose in the region of the curve where maximum sparing was observed. The graph assumes approximate equivalency between units of exposure-rate (R/min) and absorbed dose-rate (cGy/min). Also, no correction was made regarding the relative biological effectiveness of X-rays relative to gamma-rays. A graphic presentation of this form was plotted by Searle [1974] in a review of doserate effects on the production of specific locus mutations in mouse spermatogonial stem cells. Reproduced from Peng et al. [2012].

\section{Terminal Deletions, Incomplete Exchanges, and LET}

Redirecting focus for the moment, the formation of simple exchange aberrations (e.g., reciprocal translocations and dicentrics) requires the equivalent of 2 radiogenic breaks - each releasing a pair of broken ends - and thus involves the rejoining of 4 recombinationally reactive termini. Only about $15 \%$ of the DSBs promptly generated by X-rays produce a radiogenic chromosome break as measured by prematurely condensed chromatin [Cornforth and Bedford, 1983; Bedford and Goodhead, 1989]. Of these, roughly $10 \%$ will go on to form a microscopically visible chromosomal exchange aberration. Thus, by any reasonable set of assumptions, the large majority of IR-induced breaks to the chromosome must be rejoined without visible loss of continuity. In other words, most of the time the 2 reactive ends of a given chromosome break simply rejoin with one another in a process called restitution, which restores gross linear continuity to chromosome structure. Restitution is akin to the unimolecular DNA repair process of NHEJ, but since it is a cytogenetic term, it implies nothing about subtle base- 
pair-level molecular changes that may result at the rejoined breakpoint.

We previously mentioned that on rare occasion initial radiologically broken ends of a chromosome are unable to find any partner end with which to rejoin. The resulting terminal deletions produce both a centric and acentric fragment from the same chromosome. However, during the process of an attempted exchange, sometimes misrejoining does not go to completion, leaving only one of the potential break pairs unrejoined. These incomplete exchanges also produce acentric fragments that are easily (and even typically) misclassified as bona fide terminal deletions. For the argument that follows, we will consider terminal deletions as being representative of unrepaired damage - a single break that merely fails to rejoin. Exchange aberrations would then represent instances of total misrejoining, whereby all broken chromosome ends join up with "illegitimate partners." By similar analogy, incomplete exchanges represent this type of misrejoining process that has partially failed.

The preceding background on terminal deletions and incomplete exchanges is given in order to appreciate the following viewpoint concerning high versus low LET chromosome damage [for review see Ritter and Durante, 2010]. mFISH is one of the very few approaches capable of distinguishing true terminal deletions from incomplete exchanges. The distinction is an important one in the context of the following question: why is high LET IR more effective at producing CAs than the same dose of $\mathrm{X}$ - or gamma-rays? A common refrain is that the former produces lesions qualitatively distinct from that of the latter in the sense that they are more difficult to repair. On the surface, this notion appears consistent with the fact that high LET radiations produce higher yields of terminal deletions per unit dose than either $\mathrm{X}$ - or gamma-rays. However, the same is also true of all aberration types, the large majority of which are exchanges that involve complete rejoining and so are more accurately termed total misrepair events: translocations, dicentrics, rings, inversions, etc. Simply put, high LET radiations produce more aberrations of all types. But if high LET lesions contrast with low LET lesions on the basis of qualitative differences that affect rejoining, then one would expect the relative frequency of true terminals (unrepaired damage) to be much higher for high LET radiations, in order to account for their enhanced effectiveness. Yet, studies show a similarly low percentage ( $\sim 5 \%)$ of chromosomal breakpoints being due to true terminal deletions irrespective of LET. In other words, the increased yields of total CA following high LET exposures cannot be accounted for by

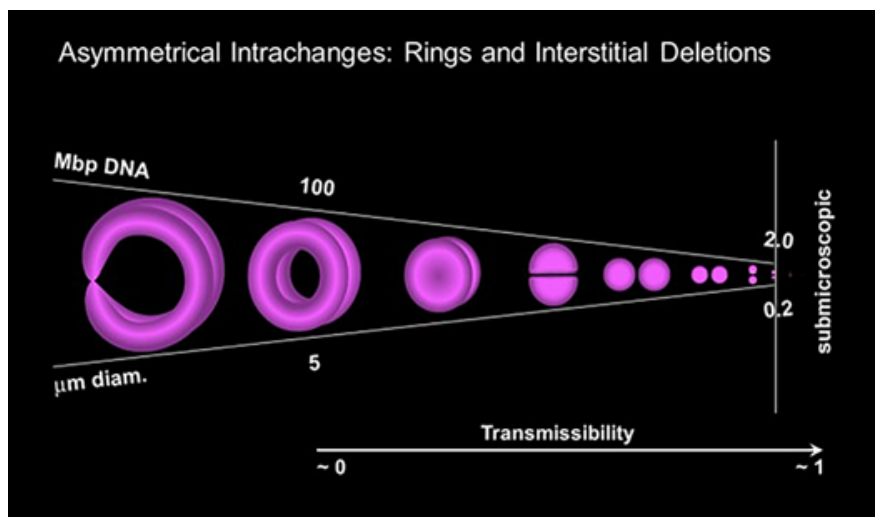

Fig. 6. The family of asymmetrical intrachanges (rings). Shown in descending order of size are the products of complete asymmetrical chromosome-type intrachanges (rings), to which the interstitial deletions (IDs) belong. Below a few megabases in size, IDs become submicroscopic. The submicroscopic threshold applies to the detection of the acentric fragments themselves by standard brightfield microscopy of Giemsa-stained specimens. The figure is meant to convey the concept that transmissibility is inversely correlated with ID size. Reproduced from Cornforth and Durante [2018].

increased yields of terminal deletions, a result at odds with the notion that high LET lesions are fundamentally and qualitatively distinct from those produced by low LET IR by virtue of repairability [Cornforth, 2021].

\section{Intrachanges}

All asymmetrical intrachromosomal rearrangements belong to the ring family, which includes large centric and acentric rings, smaller IDs and tiny "paired-dot" fragments often called double minutes (Fig. 6). All are easily visible with traditional histological solid stains. Larger intrachanges figured prominently in early attempts to establish cytogenetic methods that sought to determine whether damage to chromosomes had come from low versus high LET sources of radiation. In other words, was there a fingerprint of radiation quality? The majority of such LET-dependent biomarkers used some sort of ratio between interchanges and intrachanges, the most widely known being the F-ratio, which compares dicentrics to centric rings [Brenner and Sachs, 1994]. Despite its argued success in a number of in vitro studies, there are problems connected with the application of the F-ratio that severely limit its use. For one, the scoring of asymmetrical exchanges requires that cells carrying these CAs reach their first mitosis following irradiation, however such cells are eliminated from a dividing cell population. The same basic concept has been applied to the ratio of 


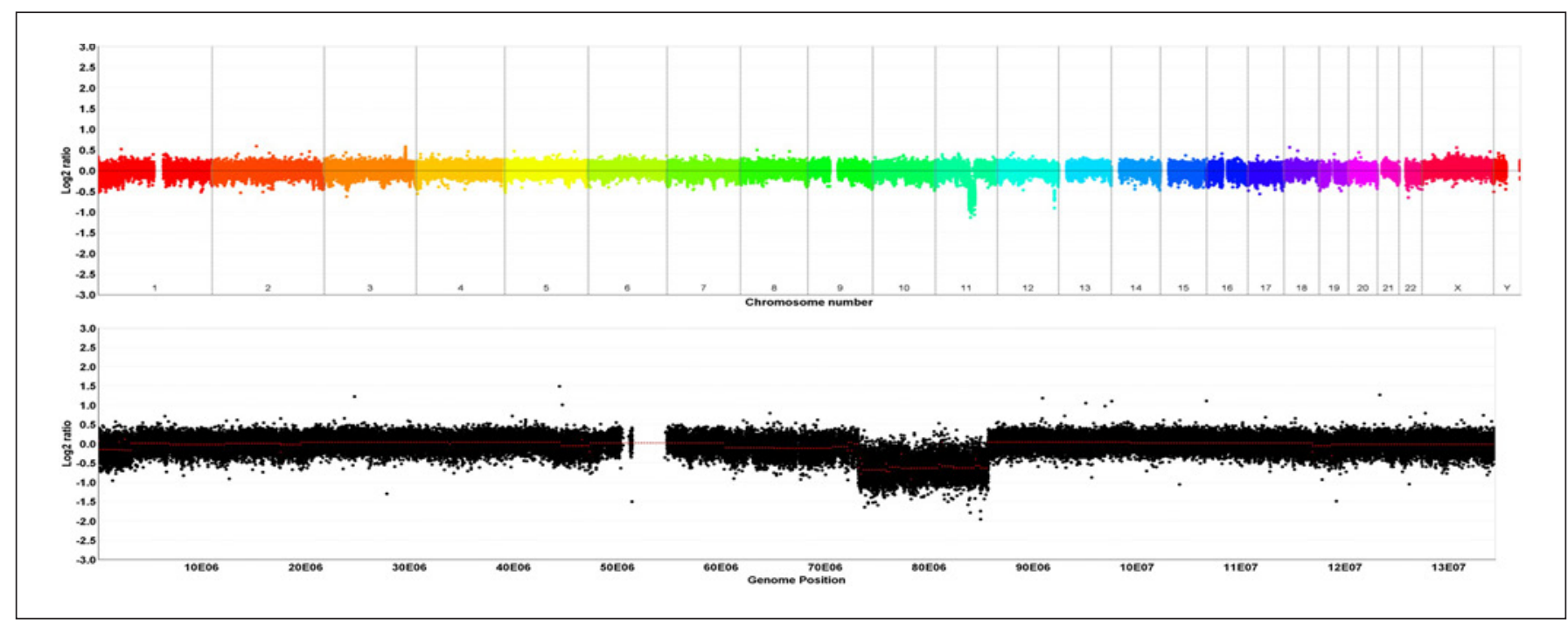

Fig. 7. High-density aCGH "rainbow plot" of DNA from a clone whose progenitor cell was exposed to 4 Gy of gamma-rays. Log2 values dipping below zero indicate deleted regions for the 24 chromosomes of the human genome. By mFISH (not shown), all cells of this clone harbored a complex interchromosomal exchange designated as $46 \mathrm{X}^{\prime}, \mathrm{Y}^{\prime}\left(\mathrm{X}^{\prime}-2-\mathrm{X}\right)\left(2^{\prime} \mathrm{T}\right)$ by mPAINT nomenclature
[Cornforth, 2001]. This indicates a segment of chromosome 2 has been inserted into the $\mathrm{X}$ chromosome, resulting in a truncated chromosome 2 . The plot shows that this mutant also contains a large 13-Mb interstitial deletion of chromosome 11. Reproduced from Cornforth and Durante [2018].

tion size distributions resulting from high versus low LET IR, although that would seem to be fertile ground for future investigation of potential fingerprints of radiation quality in connection with interchange:intrachange ratios.

\section{Symmetrical Intrachanges}

Recall that there is a near 1:1 ratio of symmetrical to asymmetrical exchanges. Couple this with the fact that asymmetrical intrachanges like IDs and double minutes are at least as frequent as other aberration types [Cornforth and Bedford, 1987]; it then becomes clear that inversions are expected to play a major role in IR-induced effects. The problem has always been in lacking the ability to detect them. As discussed above, at the cytogenetic level this is largely overcome through the use of $\mathrm{dGH}$, which is capable of detecting even small inversions with high efficiency. This implies that dGH-observable inversions could take the place of centric rings in the calculation of interchange:intrachange ratios used to calculate the aforementioned F-ratios. Likewise, transmissible translocations may be substituted for dicentrics, thereby producing an F-ratio-like metric with the advantage that it would be applicable to dividing cell populations. Of course, small transmissible asymmetrical intrachanges (IDs) seen by aCGH could serve the same purpose. 
Based on dGH analysis of irradiated human cell cultures, the induction of inversions was shown to be highly dependent on ionization density, with high LET particles producing remarkably robust (and apparently linear) dose responses compared to gamma-rays [Ray et al., 2014]. Somewhat unfortunately, despite their higher yields per unit dose compared to dicentrics, their nonirradiated background is also substantially higher. Given their high transmissibility compared to other asymmetrical CA types, this is not particularly surprising. However it does serve to place practical limitations on their use for the detection of damage following extremely low doses. Nevertheless, dGH has been successfully used for assessing chromosome damage in the peripheral blood of IRexposed human populations. For example, elevated frequencies of inversions were observed in astronauts during and after long-duration spaceflight, including NASA's first One-Year-Mission astronaut [Garrett-Bakelman et al., 2019; Afshinnekoo et al., 2020; Luxton et al., 2020a, b]. In a more biodosimetric capacity, inversions were also used to augment physical IR measurements in order to more accurately reconstruct doses absorbed by US military personnel (Atomic Veterans) involved in aboveground nuclear weapon testing post WWII [McKenna et al., 2019].

\section{Molecular Manifestations}

For structural variants like translocations and inversions, MPS offers valuable information about the specific basepairs surrounding each individual exchange breakpoint. This is where telltale "molecular fingerprints" are left behind that can be used to help discern the precise molecular repair/misrepair pathways responsible for exchange formation. An important yet often overlooked aspect of the cytogenetic paradigm is that an IR-induced exchange such as a reciprocal translocation produces 2 such junctions. For example, at $(3 ; 4)$ reciprocal translocation produces a $t(3 ; 4)$ breakpoint junction, but also a (43) junction. Only when "both sides" of the exchange event are sequenced, are we in a position to "mentally reconstruct" the entire exchange event as it took place. To our way of thinking, no other experimental approach offers this level of information content. Until rather recently, breakpoint analysis of IR-induced mutations was the only source of such information [for example Morris and Thacker, 1993; Morris et al., 1993]. This is because cell division during mutant selection results in loss of the acentric portion of the exchange. Granted, partial information can be gleaned by sequencing such breakpoint junctions - for example, basepair homologies utilized

Radiation Damage to Chromosomes during the process - but this tells us nothing about the number of basepairs resected (co-deleted) during the process. By analogy, this is rather worse than attempting to reassemble a picture puzzle with half the pieces missing.

Until now we have been discussing the analysis of changes to DNA in the context of single cells; however, the typical experimental approach involves IR exposure of large populations of cells. Considering the stochastic nature of IR-induced CAs, each affected cell within such a population will almost certainly carry its own unique constellation of genetic damage. Consequently, making sense of MPS data derived from exposed cell populations becomes a difficult, if not pointless, exercise. A glaring shortcoming of MPS - unfortunately, one that also applies to most molecular approaches - is its inherent inability to assess an endpoint on an individual cell-by-cell basis. Single-cell analysis has been successfully used in conjunction with aCGH and MPS [Klein et al., 1999; Le Caignec et al., 2006]. But this would require the construction of highly amplified error-free DNA libraries for each affected cell, so the effort becomes untenable for assessing changes to an irradiated cell population.

The issue can be circumvented by clonally expanding irradiated single cells. Since cells replicate their own genomes with much greater fidelity than even the most sophisticated PCR amplification, this strategy results in every cell within an affected clone containing identical genetic alterations, in this case, symmetrical CAs (translocations and inversions) and small/submicroscopic IDs that transmit during clonal expansion. This approach was first used to identify a gamma-ray-induced reciprocal translocation in a human cell clone by mFISH. Subsequently, the breakpoint junctions of the translocation were tentatively identified by MPS (paired-end sequencing), later to be confirmed and characterized at the nucleotide level by Sanger sequencing [Cornforth et al., 2018]. Three significant findings resulted from this effort.

Firstly, after sequencing both junctions of the translocation, it was discovered that a 1-bp and a 6-bp co-deletion had taken place during the rejoining reaction. Secondly, it was apparent that the rejoining process had taken advantage of limited short-range nucleotide homology involving 4 basepairs (microhomology). To the best of our knowledge, this represents the only published example of MPS successfully applied to human cells carrying an IR-induced CA that was first identified by cytogenetic methods. Results substantiate previous work by investigators who, using quite different experimental model systems, concluded that rejoining was driven by micro- 
homology-mediated NHEJ. For example, results similar to ours were obtained when using the homing endonuclease I-SCE to enzymatically produce DSBs by way of recognition sequences inserted into different chromosomes [Richardson and Jasin, 2000a, b]. In a broader sense, the same can be said of earlier work that examined the fine structure of IR-induced mutations at the HPRT locus. Taken together, these results are consistent with the widely-accepted view that IR-induced chromosome-type exchanges are mainly, if not solely, due to microhomologymediated NHEJ acting on DSBs at the basepair level [Seol et al., 2018]. We cannot help but reflect, with faint amusement, that this molecular paradigm fits "hand in glove" with core concepts of the venerable breakage-first hypothesis for the production of CAs put forward nearly a century ago [Stadler, 1931; Sax, 1940; reviewed in Cornforth and Bedford, 1993; Cornforth, 1998].

The third finding of significance from this study was that both breakpoints mapped to repetitive sequences; in one case a 74-bp-long interspersed nuclear element (LINE); in the other, a 64-bp-long terminal repeat (LTR). The repetitive nature and abundance of these (and other repeat sequences) present well-known difficulties to most sequencing strategies. For the bioinformatics approaches used to interpret raw MPS data, this causes multiple spurious calls to the reference genome, and a plethora of false-positive results regarding the genomic position of breakpoints. Until more IR-induced translocation breakpoints are sequenced, it is not possible to rule out the possibility that repeat involvement is indicative of some repair/misrepair pathway preference for this type of DNA. On the other hand, consider that repeat sequences of all types (e.g., LINES, SINES, LTRs, Alus) are estimated to comprise up to $60 \%$ of the human genome [de Koning et al., 2011]. Consider also the random nature of prompt IRinduced DSBs. These 2 pieces of information virtually guarantee that at least 1 breakpoint of a reciprocal translocation will land in a repetitive element by pure chance, irrespective of any sequence-dependent preference for the underlying repair pathway.

In either case, the likely solution to the sequencing problem in regard to characterizing breakpoints of structural variants will involve MPS approaches capable of making reference-genome calls to sequences that lie safely outside breakpoints that might contain DNA repeats. In contrast to the once-common approach of paired-end sequencing, these include mate-pair sequencing, which is capable of piecing together long-range fragment assemblies from short sequence reads, and single-molecule/real-time sequencing that is capable of much longer reads.
Until recently, costs associated with these newer MPS platforms have be prohibitively expensive for routine application, although pricing has fallen considerably in recent years.

\section{Homologous Recombination}

We should reiterate that the preceding discussion has centered on IR-induced aberrations of the chromosometype in diploid cells, where formation of all rearrangements is obliged to occur in the G1/G0 phases of the cell cycle. This effectively eliminates homologous recombination (HR) from consideration as a viable repair/misrepair pathway for IR-induced CA formation, mainly because the only readily available source of template homology for a damaged chromosome in G1/G0 is its corresponding homologue. Notably, exchange aberrations between homologous chromosomes occur at frequencies higher than would be expected on the basis of random break interactions. However, the overall impact of this phenomenon on break rejoining leading to CA exchange formation is miniscule [Plan et al., 2005]. Furthermore, there is direct evidence that HR is specifically repressed during G1; for example, several reports demonstrate the absence of RAD51 in G0/G1 cells, which presumably would be necessary for any sort of homology-directed repair [Flygare et al., 1996; King et al., 2017].

For most cytogeneticists, an overarching criticism of HR-directed CA formation would be that its initiation requires only a single DSB, not a pair of them. That being said, HR does find biophysical analogy with certain generalized models of radiation action that also reject the requirement for lesion-lesion interaction (e.g., break-break endjoining) [Goodhead, 1985]. Such "one-hit" models were bolstered by the interpretation of studies using extremely low energy X-rays, whose range of post-absorptive electrons is limited to a few nanometers. Evolving from these studies was the idea that a similar mechanism also applied to the formation of CAs [Griffin et al., 1998]. However, when tested at the cytogenetic level, the concept lacked experimental support [Cornforth, 1990]. Support for this idea was further eroded when it was shown that 2 enzymatically induced DSBs were required in order to produce recombinant cells containing chromosome translocations [Richardson and Jasin, 2000a]. Moreover, whereas the breakpoint junctions of these cells were associated with resection of very few basepairs, HR is wellknown for producing resection tracks that are longer by orders of magnitude.

To be clear, we do not so readily dismiss the idea that HR has an important role to play in the production of 
chromatid aberrations, mainly because these types are produced in G2 or subphases of S where the replication fork has already duplicated the region of the chromosome where an IR-induced DSB occurred. In this case, homologous information required for HR is nearby and readily available to a damaged chromatid in the form of its undamaged sister, to say nothing of the fact that S and G2 cells have ample RAD51.

While chromatid-type aberrations, shown earlier (Fig. 1b), are not the central focus of this review, it becomes necessary to discuss them in the context of repair pathways that utilize significant stretches of basepair homology. A few prominent researchers have proposed a role of HR in the repair of IR damage in S and G2 phases of the cell cycle that would ostensibly affect the formation of chromatid-type exchanges [Jeggo et al., 2011; Soni et al., 2020], and we have no reason to disagree with this assessment. This would include HR proper, and the characteristic long conversion tracks it produces. As a general feature, NHEJ operates throughout the cell cycle (including G2/S) where it almost certainly competes with HR for the same radiogenic lesions (DSBs). Other factors aside, this is a competition that HR cannot win, because NHEJ is far more robust than HR in terms of lesion processing kinetics, and is capable of handling increased lesion burden associated with higher absorbed doses [Soni et al., 2020].

When it operates as typically envisioned, HR "leaves no trace," meaning that template information is dutifully transferred from an undamaged template to the damaged chromosomal site (DSB) with no loss of genetic information and no change in chromosomal continuity in the form of recombinational crossover. In the vernacular of DNA repair, this means that it promotes symmetrical resolution of recombinational intermediates (i.e., Holliday junction). Yet crossover is precisely what a chromosome interchange would require during $\mathrm{HR}$, which implies a somewhat uncharacteristic asymmetrical resolution of the Holliday junction [Liberi and Foiani, 2010]. This would be an instance where the HR process itself leads to misrepair (Fig. 8). If HR is indeed acting in this capacity, it would not appear to offer an alternative superior to that provided by NHEJ.

However, it is one thing to ask how the HR rejoining process itself might directly produce an exchange aberration, as discussed above. It is an altogether different question to ask how HR might indirectly influence the overall yields of IR-induced CAs per unit dose. It could do this by reducing the number of DSBs available as substrates for competing misrejoining processes like NHEJ. It seems

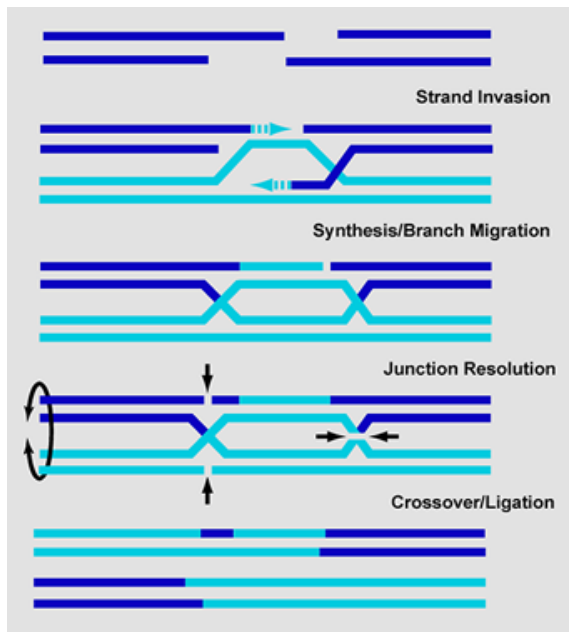

Fig. 8. Crossover within Holliday junction. The schematic shows how a single double-strand break (topmost figure) might be asymmetrically resolved through homology-directed recombinational intermediates to form a crossover that would present itself as a chromosome translocation at the cytogenetic level. This would be an example of the homologous recombination process itself directly producing an exchange aberration (bottom figure). Redrawn from Griffin and Thacker [2004].

reasonable to suggest that $\mathrm{HR}$ is capable of acting on a subclass of radiogenic DNA lesions that are poorer substrates for NHEJ. In this case, the role of HR would be to repair a subclass of DSBs otherwise destined to be rejoined by NHEJ. For example, differences in radiation track structure might produce a qualitatively distinct type of damage whose cellular response depends on its DNA repair "pathway choice" [Shibata et al., 2011; Grosse et al., 2014; Fontana et al., 2015]. The concept is succinctly exemplified by the work of Iliakis and colleagues [Mladenov et al., 2019], who present compelling evidence that during G2 phase the role of HR is highly dependent on lesion burden (DSB concentration), and therefore dose. Using $\gamma$-H2AX foci as a principle measure of damage [Sedelnikova et al., 2003], they report that for doses below 2 Gy HR effectively removes up to half the DSBs produced by gamma-rays, whereas for higher doses its repair capacity is undetectable. Significantly, these results were reflected in chromosome damage measured by G2 phase prematurely condensed chromosomes.

From a DNA sequence perspective, direct involvement of HR recombination would lead to exchange breakpoint junctions associated with long telltale conversion tracks. By contrast, the indirect effects of HR mentioned here would have the effect of reducing IR-induced yields of CAs per unit dose, simply by lowering the concentra- 
tion of DSBs available for competing repair processes like NHEJ. Otherwise, this process should not leave any measurable imprint on the sequences surrounding the breakpoint junctions of exchange aberrations. This is because G2 conversion tracks between sister chromatids would be invisible to all methods of molecular analysis that we are aware of.

\section{Are IR-Induced Mutations Chromosome Aberrations?}

In 1927, Herman Muller reported that X-rays produced phenotypically observable mutations in fruit flies [Muller, 1927b, 1928], which was quickly followed by reports of X-ray-induced mutations by Stadler and others in various plant species [Goodspeed and Olson, 1928; Stadler, 1928, 1931, 1932]. Thus, IR became the first known mutagen, and likely was the first known carcinogen, as well [Brenner, 1989]. Soon thereafter, McClintock began studies on the nature of some of the mutants Stadler had isolated, indicating that the mutants she studied were due to large chromosomal abnormalities...

"... Following my arrival at Columbia in June 1931, plants were selected where chromosomes were to be examined." (Meiotic stages were examined to look for certain kinds of events that might be responsible for the expression of recessives). . "None of the recessive phenotypes in the examined plants arose from 'gene mutation'. Each reflected loss of a segment of a chromosome that carried the wildtype allele, and $x$-rays were responsible for inducing these deficiencies. They were also responsible for producing other types of chromosomal rearrangements, some of them unexpectedly complex." [McClintock, 1931, 1984].

As time went on, many additional agents (mostly chemicals) were discovered to cause mutations, while countless others became suspect. Meanwhile, an ever-increasing focus of attention was being placed on them regarding carcinogenic effects. The fact that IR was the first known mutagen, and had also been established as a carcinogen, led to the suggestion that mutations were causally related to cancer initiation whatever the agent may be. Further, an association between chromosomal aberrations and cancer was suggested much earlier [Boveri, 1902, 1929]. Later, causal relationships between specific aberrations and particular cancers were established, as reviewed by Rowley [1990]. Because it was virtually impossible to test thousands of agents for their carcinogenic potential in mice, there was an intense interest in the development of rapid in vitro systems that would guide in predicting their carcinogenic potential.

In view of the above connections, principally 2 broad classes of assays were considered and developed. One was based on the mutagenic activity of an agent as measured in bacteria. The second was based on the "clastogenic" activity of the agent, meaning its effectiveness in producing chromosomal aberrations in mammalian cells. This latter cytogenetic approach was at the forefront of assays first adopted for this purpose, especially in connection with IR hazards [Bender and Gooch, 1962; Preston et al., 1981; Wolff, 1983; Fenech and Morley, 1985; Natarajan, 1993].

Support for the former approach using bacterial systems was sustained by the breathtaking progress and undeniable successes in molecular microbial genetics that had begun to overwhelm the study of mutagenesis, in many ways to the detriment of lessons learned by cytogenetics, which seemed forgotten or largely ignored. But to those who were uneasy about extrapolating from IR mutagenesis in E. coli to risk in humans, we were all assured that "What is true for an E. coli is also true for an elephant!"While there is undeniable truth in this, the discussion that follows serves to illustrate that for IR-induced mutagenesis in mammalian cells, "What is true for an elephant is quite often not true for an E. coli."

Invariably (and in retrospect, not surprisingly) the testing of chemical and physical agents using microbial systems led to the conclusion that small-scale intragenic events like point mutations, frameshifts, base changes, and small deletions characterized all, or the vast majority of, the kinds of mutations possible. The accepted definition became [sic] those kinds (and only those kinds) seen in microbial systems. In reports from the 1940s, and for the next 40 years, the published yields of mutants following X-ray exposure of these microbial systems were of the order of $10^{-7}$ to $10^{-8}$ mutants/cell/Gy [Demerec and Latarjet, 1946; Conkling et al., 1976; Glickman et al., 1980]. In view of these induced mutant yields, there are several expectations that might have discouraged prospects for making similar measurements in mammalian cells. For example, from the above report of Glickman and co-workers, the dose required to double the frequency of lacI mutations relative to background was $33 \mathrm{~Gy}-\mathrm{a}$ dose that reduced the fraction of $E$. coli surviving to $10^{-1}$ but would have reduced the surviving fraction of mammalian cells to around $10^{-8}$. For the sake of discussion, let's assume a similar gene under study in a mammalian cell. Since the frequency of induced mutants among the survivors of this dose would only be about $10^{-6}$, an investigator would need to inoculate some $10^{13}$ cells in each test culture or group - roughly the total number of cells in the human body - just to recover an excess of 10 induced mutant colonies! 
A particularly noteworthy observation arose in connection with the famous Ames test, a bacterial system first developed in the late 1960s, and which is still in use today [Ames and Whitfield, 1966; Ames et al., 1973]. The test was designed to predict carcinogenic potential by measuring the efficiency of an agent to produce a point or frameshift mutation that reverts the histidine-requiring auxotrophic his strain of Salmonella to histidine independence or $\mathrm{his}^{+}$prototrophy. Curiously though, IR shows up as negative in the Ames test, indicating that it is neither mutagenic nor carcinogenic - and yet, it is indisputably both! Thus, while this test remains suitable for the testing of long lists of compounds, IR is not on that list.

Another mutagenic test that measures a particular kind of point mutation utilizes the properties of Ouabain, a drug that binds to a specific region of the cell surface protein $\mathrm{Na}^{+} / \mathrm{K}^{+}$ATPase that is key to regulating of the concentration gradients of $\mathrm{Na}^{+}$and $\mathrm{K}^{+}$ions across the cell membrane. When bound to this protein, Ouabain blocks the activity of $\mathrm{Na}^{+} / \mathrm{K}^{+}$ATPase, causing cell death. There are 2 identical alleles of the gene coding for this protein, and if either one or the other suffers a point mutation affecting the Ouabain binding site of the $\mathrm{Na}^{+} / \mathrm{K}^{+}$ATPase protein, then approximately half those cell surface proteins will bind Ouabain (from the wild-type allele) inactivating it. The other half will not bind Ouabain, leaving it free to function normally and allow the mutant cell to survive and form Ouabain-resistant mutant colonies. Spontaneous background mutants occur at low frequency, and treatment of cells with UV light or alkylating agents produces easily measurable yields of Ouabain-resistant mutants. Yet to our knowledge no such mutants have ever been reported following IR exposure [Arlett et al., 1975; Cleaver, 1977; Thacker et al., 1978].

The Big Blue ${ }^{\circledR}$ mouse is a transgenic animal in which the E. coli lacI gene carried on a shuttle vector has been introduced so that every cell in the mouse has integrated about 40 tandem copies of the gene in mouse chromosome 4 [Quillardet et al., 2006]. After treatment with a mutagen, cells from various mouse tissues can be harvested, DNA isolated, and the shuttle vectors with the lacI genes packaged into viable lambda phages and tested for point mutations affecting the lacI gene function by the color of plaques on a lawn of E. coli. If the lacI gene is mutated, the lacZ gene in the E. coli will not be repressed, and thus produces $\beta$-galactosidase. With X-gal as substrate, $\beta$-galactosidase causes formation of a blue plaque, and lacI mutants can then be counted. This has been very useful for measuring many chemical mutagens. But here again, not so useful for agents that produce mostly large

Radiation Damage to Chromosomes deletions like IR, because such mutants will not be recovered for measurement.

Before moving on, let's stop to clarify key points about the experimental systems we have discussed thus far. All 3 are capable of recovering mutations induced by a wide variety of chemical agents, the vast majority of which are caused by are small intragenic changes: basepair transitions/transversions, frameshifts, and small basepair-level deletions. But they are virtually incapable of detecting IRinduced mutations in mammalian cells. It is also worth noting that the point mutational changes these sorts of assays measure are typically subject to reversion back to the wild type. By contrast, IR-induced mutations in mammalian cells seldom revert, further underscoring the point that they are not caused by small intragenic lesions.

\section{Mammalian Somatic Cell Mutagenesis}

The picture became increasingly clear when numerous reports began appearing that described experimental systems specifically designed for studying mutagenesis in cultured mammalian cells. These led to a much better understanding and redefinition of what kinds of mutations are actually involved. For IRs, it turns out that hardly any of the mammalian cell mutants from radiation exposure are point mutations. There are several extensive reviews pertaining to this topic [Thacker and Cox, 1983; Bedford and Dewey, 2002]. A few examples supporting this conclusion are summarized below, starting with the venerable HPRT system.

Mutation at the X-linked HPRT locus in diploid mammalian somatic cells is possible because male cells have only $1 \mathrm{X}$ chromosome and females have only 1 active X, so a mutation severely affecting the product of the active allele can be measured as soon as the pre-existing enzyme has disappeared from the surviving mutant or its progeny [Caskey and Kruh, 1979]. The HPRT enzyme is key to the purine salvage pathway, and without it the cell cannot incorporate toxic purine analogs such as 6-thioguanine (6TG), which would otherwise kill it. In other words, HPRT mutants become resistant to 6-TG and form colonies in the presence of the drug while non-mutant cells are killed. If, instead of being X-linked, the gene had been located on an autosome with 2 active alleles, one on each of the 2 homologs involved, knocking out only 1 allele would still allow lethal incorporation due the continued supply of HPRT from the remaining intact allele. In any case, numerous studies on the X-ray dose-response for HPRT mutants report yields of about $2 \times 10^{-5}$ per Gy [Thacker et al., 1977; Jostes et al., 1980]. This is some 20- to 200-fold higher than the X-ray induced yields typically reported 
for microbial systems mentioned above. Why should there be such a large difference? Do X- or gamma-rays produce some (or any) point mutations? To answer this question, we first consider the fine structure of the HPRT gene itself, whose total size is about $44 \mathrm{~kb}$. The 9 coding exons it contains make up a mere $1,364 \mathrm{bp}(3 \%)$ of its sequence; the rest consists of introns. Several studies seeking to determine the nature of IR-induced mutations at this locus have implemented multiplex PCR for the purpose of detecting the presence of amplification products from primer pairs flanking some or all of the individual 9 exons.

The overall consensus from these studies is that the majority of recovered mutants harbored deletions of some (and in some cases all) of the 9 exons. From the preceding discussion, this should come as no surprise. The issue we now raise has to do with the molecular nature of those 6-TG-resistant mutants whose PCR profile is normal. The default assumption has always been they are small basepair changes that escape detection by PCR, but is this really the case? Thinking in terms of exchange breakpoints, a translocation of part of the gene to another chromosome or another part of the X chromosome would very likely destroy the gene product, but would not affect the multiplex PCR amplification signal. An exontargeted PCR test would not rule this out, and the following "back-of-the-envelope" calculation can be made in support of this proposition.

A dose of 4 Gy will produce about 1 dicentric and 1 ID per cell, which combined constitute 4 exchange breakpoints. These are most likely lethal but, as we have discussed, there will be an approximately equal number of non-lethal and transmissible balanced translocations and inversions also produced and randomly distributed among cells in an irradiated population. The size of the $44-\mathrm{kb} H P R T$ gene as a fraction of the $6 \times 10^{9} \mathrm{bp}$ contained in the human diploid genome is about $7.3 \times 10^{-6}$. The likelihood that one of the 4 break points will occur within the HPRT region will then be $4 \times 7.3 \times 10^{-6}=2.9 \times 10^{-5}$. On a per Gy basis, this translates back to roughly $0.7 \times$ $10^{-5}$ mutants per Gy, which compares rather favorably with observed yields that fall in a range of ( 1 to 3$) \times 10^{-5}$ HPRT mutants per Gy.

Not all potential exchange breakpoints produced by IR will result in rearrangements large enough to see under the microscope, but that only serves to sharpen our argument. The point we endeavor to make through these calculations is that there are more than enough exchange breakpoints to explain IR-induced mutant yields at the HPRT locus. For that reason, we are skeptical that PCR- negative mutants should be considered to represent "point mutations" by default. As it turns out, our skepticism enjoys substantial support through the work of Lobrich and colleagues [Rothkamm et al., 2008], who investigated X-ray damage to this locus by taking a more direct molecular approach. These authors reported that in addition to the majority of mutations involving part or all of the HPRT gene, $\geq 20 \%$ of 6 -TG mutants yielded normal multiplex PCR patterns for all 9 HPRT exons, but often failed to amplify the corresponding cDNA of the gene. Furthermore, when subjected to hybridization analysis following Not I restriction, most of the PCR-negative mutants showed altered exon fragment sizes. They concluded that "intrachromosomal [intronic] rearrangements on the Mbp scale represent the prevailing type of radiation-induced HPRT mutations." Given the benefit of $\mathrm{dGH}$, which had not been widely available to the research community at the time, we imagine the authors would have identified these "intrachromosomal rearrangements" for what they almost certainly were, namely small paracentric inversions. Deletions in which the entire HPRT gene is deleted also occur, and these will contribute to mutation yield, so long as an essential neighboring gene is not co-deleted. This brings up the point exemplified by mutagenesis at the thymidine kinase $(T K)$ locus.

The TK mutation assay measures mutations involving the autosomal linked TK locus on chromosome 17 in humans and chromosome 11 in mice. Diploid wild-type cells with the genotype $T K^{+/+}$are killed when they incorporate trifluorothymidine (TFT), which requires thymidine kinase. Without this enzyme cells do not incorporate the drug and are unaffected. It would be very rare to find a TFT resistant mutant following irradiation of $\mathrm{TK}^{+/+}$ cells, as this would require a mutation in both alleles, so investigators first isolated $\mathrm{TK}^{+/-}$strains that were heterozygous at this locus [Clive et al., 1972]. After irradiation of $\mathrm{TK}^{+/-}$cells and incubation in the presence of TFT, only cells suffering mutation of the remaining wild-type allele, producing a $T K^{-/-}$genotype, will form colonies, while the remaining $T K^{+/-}$cells will die. Using this system, results of studies on the sensitivity for TK mutation by X-rays were reported in the range of 350 to $2,300 \times 10^{-6} / \mathrm{Gy}$ for mouse cells [Evans et al., 1985] and 30 to $1,200 \times 10^{-6} / \mathrm{Gy}$ for human cells [Liber and Thilly, 1982]. When both TK and HPRT sensitivities were measured in the same cells, which is the most valid experimental design for comparison, the yields per Gy for the TK mutants were as much as 50- to 100-fold higher than for HPRT mutants [Liber et al., 1989], which would be some 10,000-fold higher 
than is typical for microbial systems! The explanation suggested for this additional difference was that mutations involving relatively large deletions would remain viable even if a few essential genes were co-deleted so long as the deficiency could be complemented by active alleles still present on the intact homolog.

Another experimental approach that measures an upper limit of sensitivity regarding $\mathrm{X}$-ray induced mutation yield per $\mathrm{Gy}$ is the $\mathrm{A}_{\mathrm{L}}$ system, which uses a $\mathrm{CHO} /$ human hybrid cell that contains a single copy of human chromosome 11 where the CD59 gene is located [Waldren et al., 1979; Wilson et al., 1999]. The gene product $A_{L}$ is an antigen located on the cell surface that can be targeted by an anti- $A_{L}$ antibody. In the presence of the antibody and complement, the cells with $A_{L}$ on their surface are killed. However, if CD59 on human chromosome 11 is physically or functionally lost, the antibody has no target, so the cell will survive and form a colony. Using the $A_{L}$ system to study X-ray mutagenesis, Waldren et al. [1979] found a mutational sensitivity to X-rays for CD59 that produced mutant yields of around $10^{-3} / \mathrm{Gy}$. This value is a little higher than, but in general agreement with, that for TK mutants. However, it was nearly 2 orders of magnitude larger than even that reported for HPRT mutations! Molecular analyses by measurement of simultaneous loss of various other markers on this chromosome showed that virtually all were very large deletions, but that following exposure to UVC light or alkylating agents, most were point mutations.

For those reluctant to abandon the idea that IR mutagenesis was largely the result of point mutations, it must have seemed difficult to concede the obvious. There was nothing "wrong" with the experimental systems they had been using. They were fine for what they were designed to do, measure small basepair changes. Unfortunately, their use led to a gross underestimate of somatic cell mutagenesis caused by large-scale rearrangements. By the 1980s, the handwriting was on the wall and the idea that there was a simple equivalence between X-ray mutagenesis in microbial and mammalian cells was quietly abandoned, at least by those who had been following the controversy.

\section{Heritable Mutations and CAs}

Public consciousness toward the biological effects of IR on human populations rose sharply after the atomic bombings of Hiroshima and Nagasaki. A particular area of interest was heritable mutations in the offspring of irradiated parents in view of what was already known about mutagenic effects of X-rays in drosophila [Muller, 1927a], later to include large-scale studies in mice [Russell, 1951]. The Atomic Bomb Casualty Commission (ABCC) was formed in 1947 [Putnam, 1998] and later reorganized as the Radiation Effects Research Foundation (RERF) in 1975 [Shigematsu and Mendelsohn, 1995], a joint venture between US and Japanese governments for the purpose of studying the health effects of radiation on Japanese Abomb survivors.

Prompt emissions from atomic bomb radiation include energetic gamma-rays and a smaller dose contribution from neutrons, the biological effects of which are well studied. Several interesting but conflicting reports appeared between 1994 and 2004 concerning radiation induction of germline mutations at hypervariable minisatellite loci in both mice and humans. In the mouse studies, Dubrova et al. [1998] reported significant induction of these mutations, while Sadamoto et al. [1994] did not. For the human studies, there is also disagreement. Minisatellite mutation induction in irradiated humans was reported in connection with the Chernobyl accident [Dubrova et al., 1996], yet the RERF found no such mutation induction in A-bomb survivors [Kodaira et al., 2004]. Clearly, this apparent dispute needs to be sorted out before further consideration is given to the results involving the mutability of minisatellite sequences with respect to F1 transmissibility.

This controversy aside - and contrary to expectations based on the mouse studies, as well as belief among the lay public - a clear demonstration of transgenerational mutagenic effects in humans is yet to be demonstrated. Epidemiological attention gradually shifted away from mutations in the $\mathrm{F} 1$ progeny to various cancers that began to appear some years later in exposed (F0) individuals. As with other studies, cancer induction rates (per unit dose) were found to be much higher than could be demonstrated for heritable mutations. Consequently, guidance for radiation protection standards - once based on parameters like mutation doubling dose - were instead directed toward risk of cancer for individuals.

Despite a paucity of direct experimental evidence, transmissible IR-induced mutations in humans continue to be a subject of interest [Nakamura, 2006; Grant et al., 2015]. We mention all of this in connection with our previous discussion on nonlethal CAs like reciprocal translocations and inversions, and in keeping with the above arguments that most IR-induced mutants in somatic cells involve large-scale genomic rearrangements such as CAs, as opposed to small basepair changes. This is an important point for the discussion that follows, because in order for a chromosomal rearrangement to produce a mutation 
- for example, as the result of a breakpoint occurring within a gene of interest or controlling element - its transmissibility is paramount.

Long-term transmissibility of CAs from irradiated parents to their F1 progeny is inextricably linked to gametogenesis. For logistical and experimental reasons, studies of this type have involved the irradiation of male mice. Abnormal synaptonemal structures found at pachytene or diakinesis stages of meiotic prophase are distinctly indicative of chromosome translocations, and these structures have been found in F1 generations [Kalikinskaya et al., 1986] in cells that were irradiated in the haploid post-meiotic stages of spermatogenesis (e.g., secondary spermatocytes, spermatids). From the standpoint of radiation protection these would be of lesser concern, because within a few weeks of irradiation they are depleted from the reproductive tract, being replaced by cells exposed earlier in the "reproductive queue." IR damage to the primordial spermatogonial stem cell compartment is of utmost concern, since translocations and inversions occurring there offer a perpetual fixed source of CAs that will later find their way to the $2 \mathrm{n}$ primary spermatocyte, and later to the $1 \mathrm{n}$ mature sperm. It follows that all somatic cells of such an affected individual would also carry the translocation, though we are aware of only one comprehensive study investigating this premise. The RERF looked for chromosome aberrations in the peripheral blood of over 8,000 children born to exposed atomic bomb survivors of Hiroshima and Nagasaki [Awa et al., 1968]. While the study showed clear evidence of familial transmission of chromosome rearrangements - mostly translocations and inversions - it failed to detect any difference in aberration frequencies between exposed and control groups.

Translocations or inversions arising in a parental gamete can lead to a heterozygosity in the F1, resulting in translocation or inversion heterozygotes. Although every cell in the body of such offspring contains the translocation or inversion, they are phenotypically normal, except for a problem when producing gametes of their own. For a translocation heterozygote, the synaptonemal pairing of homologs and subsequent chromosome segregation alternatives in meiosis results in semi-sterility. Half the gametes are patently non-viable because of deletion/duplication of genetic material. Of the remaining half, $25 \%$ are normal and $25 \%$ carry the original translocation. The translocation heterozygote individual is therefore semisterile.

The situation is quite different for inversion heterozygotes where, during meiotic pairing with its normal ho- molog, an inversion loop is formed. By itself this is not a problem and the meiotic segregants will all be viable: half will contain the inversion and half the normal homolog. Importantly, however, if a crossover event occurs within the inversion loop, then only half the gametes will be viable. Thus, translocation heterozygotes are obligated to semi-sterility, whereas the viability of gametes from inversion heterozygotes is entirely dependent on whether or not crossover has occurred within the inverted region. Consequently, the innate capacity for inversions to transmit is greater than that of translocations. Of parenthetical interest, we note that virtually all inversions within the $\mathrm{X}$ chromosomes of male gametes should transmit since, aside from a small pseudo-homologous region it shares with the $\mathrm{Y}$ chromosomes, $\mathrm{X}$ crossover is not possible.

It is interesting to consider the familial transmission of aberration-bearing gametes in the context of 2 large contemporary studies involving IR mutagenesis in mice, collectively referred to as the "megamouse" experiments. Conducted separately at the Harwell Laboratory in England and at the Oak Ridge National Laboratory in the US, IR-induced mutations at several loci were investigated in F1 heterozygotes by way of readily observable traits such as coat color. Based on the understanding of mutagenesis at the time, and for many years thereafter, the identity of mutations under study were assumed to be point mutations and other small basepair changes. This, despite the objections of prominent investigators who later vociferously argued that they were more likely caused by largescale structural changes to the genome akin to chromosome aberrations [Abrahamson and Wolff, 1976; Russell and Hunsicker, 2012].

Interestingly, translocation heterozygotes have not yet been found in the offspring of atomic bomb survivors, a result that has yet to be fully explained [Kodama, 1991]. From the preceding discussion, we know that chromosome translocations produced in premeiotic gametes of an irradiated parent have a reduced transmissibility since half the resulting mature gametes are inviable and only half of the viable gametes bear the translocation. In contrast, transmissibility is inherently greater for inversions since segregation problems during meiosis I arise only when crossover occurs between the 2 breakpoints of the inverted region.

It is well-known that the frequency of crossover is proportional to chromosome length; in fact, this is the fundamental premise of genetic mapping. It then follows that the probability of inversions surviving gametogenesis is inversely proportional to their size, meaning that small inversions are likely to escape the gauntlet posed by the 
meiotic mechanism, thereby transmitting to F1 offspring. The frequency of crossovers in meiosis is estimated to be roughly 1 per $50 \mathrm{Mb}$. If we assume that an average microscopically visible ID is roughly $1 \mathrm{Mb}$ in length [Cornforth and Durante, 2018], then the odds of a crossover occurring within a region this size would be only about 1 in 50 , or $2 \%$. In other words, nearly all the inversions of this size produced in gametes would be expected to be fully transmissible to the F1 generation. As discussed earlier, our ability to detect inversions, especially small ones, has historically been poor, but now is greatly improved by $\mathrm{dGH}$ technology and may be useful for this purpose. The test does not require examination of meiotic cells for the presence and quantity of inversions, but only somatic cells, such as peripheral blood lymphocytes, from individuals whose parents had or had not been irradiated.

In summary of this section, we conclude that IR-induced frequencies of small inversions per unit dose is higher than that for translocations [Ray et al., 2014], and their transmissibility is ostensibly higher. On that basis it seems reasonable to suggest the use of small inversions in F1 progeny as a measure of transgenerational radiation effects. Such a test would not require the direct examination of gametes for the presence and quantity of inversions, but could be used on somatic cells such as peripheral blood lymphocytes from individuals whose parents were suspected of having been exposed to IR. We think this a more reasoned approach than the analysis of SNPs and other small basepair changes. Not because IR is incapable to producing these changes - it most certainly does effect these sorts of changes - but because these sorts of lesions are not unique to IR. As we have seen, our oncepoor ability to detect small inversions is now greatly improved through the use of state-of-the-art cytogenetics methodologies, and it is our contention that modern genome sequencing approaches are poised to further enhance this ability.

\section{Conclusions - Parting Comments}

It is an undeniable fact that the vast majority of radiobiological knowledge amassed over the past several decades has been biophysical in nature, where traditional cytogenetics has played a pivotal role. However, recent years have witnessed a merging of cytogenetics and molecular biology, creating a new field of study that might rightly be called "cytogenomics." As we have argued, this merger stands to expose some dubious beliefs concerning IR-induced damage to chromosomal structure. The state of knowledge and unresolved issues in radiation cytogenetics were presented in the form of a summary of proceedings of the 10th International Conference on Chromosomal Aberrations [Durante et al., 2013]. The current review provides a fuller context to some of those same issues. It is our hope that the discussion of newer methodologies has helped to sharpen the focus on those questions that remain.

Some may assert that the elegant biophysical approach has begun to reap diminishing returns, and that the prudent path forward is to hasten cytogenetics into the molecular realm. While in general agreement on this point, we would add the following cautionary note. All techniques, new and old, tend to focus on problems they are most adept at addressing, not necessarily those of fundamental significance. The adage "To those with only a hammer, the whole word is a nail" applies. Since its inception, cytogenetics has been embroiled in a number of contentious and key arguments relating to fundamental actions of IR on living cells, in many cases serving to identify and frame those same arguments. It stands to reason that new ideas and theories stemming from the implementation of modern molecular strategies should, as a primary impetus, seek harmony with the substantially rich cytogenetic experience. The fact that chromosomal aberrations are shown to underlie the most important biological effects of IR underscores this conclusion.

\section{Acknowledgements}

We thank Dr. Ralf Kittler for helpful comments related to use of MPS, and Dr. Nori Nakamura for insights related to germline transmissibility.

\section{Conflict of Interest Statement}

M.N.C., J.S.B., and S.M.B. are cofounders and Scientific Advisory Board members of KromaTiD, Inc.

\section{Funding Sources}

Studies were supported by the National Aeronautics and Space Administration (NASA): NNX15AG747G (M.N.C) and 80NSSC19K0434 (S.M.B.).

\section{Author Contributions}

All authors analyzed data, exchanged ideas, and edited the manuscript. 


\section{References}

Abrahamson S, Wolff S. Re-analysis of radiationinduced specific locus mutations in the mouse. Nature. 1976;264:715-9.

Afshinnekoo E, Scott RT, MacKay MJ, Pariset E Cekanaviciute E, Barker R, et al. Fundamental Biological Features of Spaceflight: Advancing the Field to Enable Deep-Space Exploration. Cell. 2020;183:1162-84.

Ames BN, Whitfield HJ. Frameshift Mutagenesis in Salmonella. Cold Spring Harb Symp Quant Biol. 1966;31:221-5.

Ames BN, Durston WE, Yamasaki E, Lee FD. Carcinogens are mutagens: a simple test system combining liver homogenates for activation and bacteria for detection. Proc Natl Acad Sci USA. 1973;70:2281-5.

Anderson RM, Marsden SJ, Bristow AE, Goodhead DT. Chromosomal Biomarkers of Exposure to High-Let Radiation Revealed by FISH and M-FISH Techniques. Symposium Abstract. San Juan, Puerto Rico: 48th Annual Meeting of Radiation Research Society; 2001.

Anderson RM, Stevens DL, Goodhead DT. MFISH analysis shows that complex chromosome aberrations induced by alpha-particle tracks are cumulative products of localized rearrangements. Proc Natl Acad Sci USA. 2002;99:12167-72.

Ardui S, Ameur A, Vermeesch JR, Hestand MS Single molecule real-time (SMRT) sequencing comes of age: applications and utilities for medical diagnostics. Nucleic Acids Res. 2018 46:2159-68

Arlett CF, Turnbull D, Harcourt SA, Lehmann AR, Colella CM. A comparison of the 8-azaguanine and ouabain-resistance systems for the selection of induced mutant Chinese hamster cells. Mutat Res. 1975;33:261-78.

Awa AA, Bloom AD, Yoshida MC, Neriishi S, Archer PG. Cytogenetic Study of the Offspring of Atom Bomb Survivors. Nature. 1968;218: $367-8$.

Bailey SM, Bedford JS. Studies on chromosome aberration induction: what can they tell us about DNA repair? DNA Repair (Amst). 2006;5:1171-81.

Bailey SM, Cornforth MN. Telomeres and DNA double-strand breaks: ever the twain shall meet? Cell Mol Life Sci. 2007;64:2956-64.

Bailey SM, Goodwin EH, Meyne J, Cornforth MN. CO-FISH reveals inversions associated with isochromosome formation. Mutagenesis. 1996a;11:139-44.

Bailey SM, Meyne J, Cornforth MN, McConnell TS, Goodwin EH. A new method for detecting pericentric inversions using COD-FISH. Cytogenet Cell Genet. 1996b;75:248-53.

Bailey SM, Cornforth MN, Ullrich RL, Goodwin EH. Dysfunctional mammalian telomeres join with DNA double-strand breaks. DNA Repair (Amst). 2004a;3:349-57.

Bailey SM, Goodwin EH, Cornforth MN. Strandspecific fluorescence in situ hybridization: the CO-FISH family. Cytogenet Genome Res. 2004b;107:14-7.
Bashir A, Volik S, Collins C, Bafna V, Raphael BJ. Evaluation of paired-end sequencing strategies for detection of genome rearrangements in cancer. PLoS Comput Biol. 2008; 4 : e1000051.

Bedford JS, Dewey WC. Historical and Current Highlights in Radiation Biology: Has Anything Important Been Learned by Irradiating Cells? Radiat Res. 2002;158:251-91.

Bedford JS, Goodhead DT. Breakage of human interphase chromosomes by alpha particles and X-rays. Int J Radiat Biol. 1989;55:211-6.

Bedford JS, Mitchell JB, Griggs HG, Bender MA. Radiation-induced cellular reproductive death and chromosome aberrations. Radiat Res. 1978;76:573-86.

Behjati S, Gundem G, Wedge DC, Roberts ND, Tarpey PS, Cooke SL, et al. Mutational signatures of ionizing radiation in second malignancies. Nat Commun. 2016;7:12605.

Bender MA, Gooch PC. Types and rates of x-rayinduced chromosome aberrations in human blood irradiated in vitro. Proc Natl Acad Sci USA. 1962;48:522-32.

Bender MA, Griggs HG, Bedford JS. Mechanisms of chromosomal aberration production. 3 . Chemicals and ionizing radiation. Mutat Res. 1974;23:197-212.

Bickmore WA . Karyotype Analysis and Chromosome Banding. eLS. 2001.

Boveri T. Über mehrpolige Mitosen als Mittel zur Analyse des Zellkerns. Stuber; 1902.

Boveri T. The origin of malignant tumors. Baltimore: The Williams \& Wilkins Company; 1929.

Boyle S, Gilchrist S, Bridger JM, Mahy NL, Ellis JA, Bickmore WA. The spatial organization of human chromosomes within the nuclei of normal and emerin-mutant cells. Hum Mol Genet. 2001;10:211-9.

Brenner DJ. Radon: risk and remedy. New York: W.H. Freeman; 1989.

Brenner DJ. Direct biological evidence for a significant neutron dose to survivors of the $\mathrm{Hi}$ roshima atomic bomb. Radiat Res. 1996; 145(4):501-7.

Brenner DJ, Sachs RK. Chromosomal "fingerprints" of prior exposure to densely ionizing radiation. Radiat Res. 1994;140:134-42.

Brenner DJ, Sachs RK. Comments on "Comment on the ratio of chromosome-type dicentric interchanges to centric rings for track-clustered compared with random breaks" by Savage and Papworth (Radiat. Res. 146, 236-240, 1996). Radiat Res. 1996; 146:241-2.

Brown JM, Kovacs MS. Visualization of nonreciprocal chromosome exchanges in irradiated human fibroblasts by fluorescence in situ hybridization. Radiat Res. 1993;136:71-6.

Caskey CT, Kruh GD. The HPRT locus. Cell. 1979:16:1-9.

Caspersson T, Haglund U, Lindell B, Zech L. Radiation-induced non-random chromosome breakage. Exp Cell Res. 1972;75:541-3.
Cleaver JE. Induction of thioguanine- and ouabain-resistant mutants and single-strand breaks in the DNA of Chinese hamster ovary cells by $3 \mathrm{H}$-thymidine. Genetics. 1977;87: 129-38.

Clive D, Flamm WG, Machesko MR, Bernheim NJ. A mutational assay system using the thymidine kinase locus in mouse lymphoma cells. Mutat Res. 1972;16:77-87.

Conkling MA, Grunau JA, Drake JW. GammaRay Mutagenesis in Bacteriophage T4. Genetics. 1976;82:565-75.

Cornforth MN. Testing the notion of the one-hit exchange. Radiat Res. 1990;121:21-7.

Cornforth MN. Radiation-Induced Damage and the Formation of Chromosomal Aberrations. In: Nickoloff JA, Hoekstra M, editors. DNA Damage and Repair. Clifton: Humana Press; 1998. p. $559-85$

Cornforth MN. Analyzing radiation-induced complex chromosome rearrangements by combinatorial painting. Radiat Res. 2001;155: 643-59.

Cornforth MN. Perspectives on the formation of radiation-induced exchange aberrations. DNA Repair (Amst). 2006;5:1182-91.

Cornforth MN. Occam's broom $(*)$ and the dirty DSB: cytogenetic perspectives on cellular response to changes in track structure and ionization density. Int J Radiat Biol. 2021;97: 1099-108.

Cornforth MN, Bedford JS. X-ray--induced breakage and rejoining of human interphase chromosomes. Science. 1983;222:1141-3.

Cornforth MN, Bedford JS. A quantitative comparison of potentially lethal damage repair and the rejoining of interphase chromosome breaks in low passage normal human fibroblasts. Radiat Res. 1987;111:385-405

Cornforth MN, Bedford JS. Ionizing Radiation Damage and Its Early Development in Chromosomes. Adv Radiat Biol. 1993;17:423-96.

Cornforth MN, Durante M. Radiation quality and intra-chromosomal aberrations: Size matters. Mutat Res Genet Toxicol Environ Mutagen. 2018;836(Pt A):28-35.

Cornforth MN, Loucas BD. A Cytogenetic Profile of Radiation Damage. Radiat Res. 2019;191: 1-19.

Cornforth MN, Meyne J, Littlefield LG, Bailey SM, Moyzis RK. Telomere staining of human chromosomes and the mechanism of radiation-induced dicentric formation. Radiat Res. 1989;120:205-12.

Cornforth MN, Bailey SM, Goodwin EH. Dose responses for chromosome aberrations produced in noncycling primary human fibroblasts by alpha particles, and by gamma rays delivered at sublimiting low dose rates. Radiat Res. 2002a; 158:43-53.

Cornforth MN, Greulich-Bode KM, Loucas BD, Arsuaga J, Vazquez M, Sachs RK, et al. Chromosomes are predominantly located randomly with respect to each other in interphase human cells. J Cell Biol. 2002b;159:237-44. 
Cornforth MN, Anur P, Wang N, Robinson E, Ray FA, Bedford JS, et al. Molecular Cytogenetics Guides Massively Parallel Sequencing of a Radiation-Induced Chromosome Translocation in Human Cells. Radiat Res. 2018; 190:88-97.

Cremer T, Cremer C. Chromosome territories, nuclear architecture and gene regulation in mammalian cells. Nat Rev Genet. 2001;2:292301.

Cremer T, Kreth G, Koester H, Fink RH, Heintzmann R, Cremer M, et al. Chromosome territories, interchromatin domain compartment, and nuclear matrix: an integrated view of the functional nuclear architecture. Crit Rev Eukaryot Gene Expr. 2000;10: 179-212.

Croft JA, Bridger JM, Boyle S, Perry P, Teague P, Bickmore WA. Differences in the localization and morphology of chromosomes in the human nucleus. J Cell Biol. 1999;145:1119-31.

de Koning APJ, Gu W, Castoe TA, Batzer MA, Pollock DD. Repetitive elements may comprise over two-thirds of the human genome. PLoS Genet. 2011;7:e1002384.

Demerec M, Latarjet R. Mutations in Bacteria Induced by Radiations. Cold Spring Harb Symp Quant Biol. 1946;11:38-50.

Dubrova YE, Nesterov VN, Krouchinsky NG, Ostapenko VA, Neumann R, Neil DL, et al. Human minisatellite mutation rate after the Chernobyl accident. Nature. 1996;380:683-6.

Dubrova YE, Plumb M, Brown J, Fennelly J, Bois P, Goodhead D, et al. Stage specificity, dose response, and doubling dose for mouse minisatellite germ-line mutation induced by acute radiation. Proc Natl Acad Sci USA. 1998;95:6251.

Durante M, Bedford JS, Chen DJ, Conrad S, Cornforth MN, Natarajan AT, et al. From DNA damage to chromosome aberrations: joining the break. Mutat Res. 2013;756:5-13.

Dutrillaux B, Lejeune J. [A new technic of analysis of the human karyotype]. C R Acad Hebd Seances Acad Sci D. 1971;272:2638-40.

Dutrillaux B, Sabatier L, Al Achkar W, Muleris M, Aurias A, Couturier J, et al. Radiation induced inversions in human somatic cells. Ann Genet. 1986;29:189-94.

Edelmann P, Bornfleth H, Zink D, Cremer T, Cremer C. Morphology and dynamics of chromosome territories in living cells. Biochim Biophys Acta. 2001;1551:M29-39.

Evans HH, Horng M-F, Mencl J, Glazier KG, Beer JZ. The Influence of Dose Rate on the Lethal and Mutagenic Effects of X-rays in Proliferating L5178Y Cells Differing in Radiation Sensitivity. Int J Radiat Biol Relat Stud Phys Chem Med. 1985;47:553-62.

Fenech M, Morley AA. Measurement of micronuclei in lymphocytes. Mutat Res. 1985;147:2936.

Flygare J, Benson F, Hellgren D. Expression of the human RAD51 gene during the cell cycle in primary human peripheral blood lymphocytes. Biochim Biophys Acta. 1996;1312:2316
Fontana AO, Augsburger MA, Grosse N, Guckenberger M, Lomax AJ, Sartori AA, et al. Differential DNA repair pathway choice in cancer cells after proton- and photon-irradiation. Radiother Oncol. 2015;116:374-80.

Friedland W, Paretzke HG, Ballarini F, Ottolenghi A, Kreth G, Cremer C. First steps towards systems radiation biology studies concerned with DNA and chromosome structure within living cells. Radiat Environ Biophys. 2008;47:49-61.

Garrett-Bakelman FE, Darshi M, Green SJ, Gur RC, Lin L, Macias BR, et al. The NASA Twins Study: A multidimensional analysis of a yearlong human spaceflight. Science. 2019;364: eaau8650.

Glickman BW, Rietveld K, Aaron CS. $\gamma$-ray induced mutational spectrum in the lacI gene of Escherichia coli: Comparison of induced and spontaneous setra at the molecular level. $\mathrm{Mu}$ tat Res. 1980;69:1-12.

Goodhead DT. Saturable repair models of radiation action in mammalian cells. Radiat Res Suppl. 1985;8:S58-67.

Goodhead DT. The initial physical damage produced by ionizing radiations. Int J Radiat Biol. 1989;56:623-34.

Goodspeed TH, Olson AR. The Production of Variation in Nicotiana Species by X-Ray Treatment of Sex Cells. Proc Natl Acad Sci USA. 1928;14:66-9.

Goodwin E, Meyne J. Strand-specific FISH reveals orientation of chromosome 18 alphoid DNA. Cytogenet Cell Genet. 1993;63:126-7.

Grant EJ, Furukawa K, Sakata R, Sugiyama H, Sadakane A, Takahashi I, et al. Risk of death among children of atomic bomb survivors after 62 years of follow-up: a cohort study. Lancet Oncol. 2015;16:1316-23.

Griffin CS, Thacker J. The role of homologous recombination repair in the formation of chromosome aberrations. Cytogenet Genome Res. 2004;104:21-7.

Griffin CS, Hill MA, Papworth DG, Townsend KM, Savage JR, Goodhead DT. Effectiveness of $0.28 \mathrm{keV}$ carbon $\mathrm{K}$ ultrasoft X-rays at producing simple and complex chromosome exchanges in human fibroblasts in vitro detected using FISH. Int J Radiat Biol. 1998;73:591-8.

Grosse N, Fontana AO, Hug EB, Lomax A, Coray A, Augsburger M, et al. Deficiency in homologous recombination renders mammalian cells more sensitive to proton versus photon irradiation. Int J Radiat Oncol Biol Phys. 2014;88:175-81.

Hande MP, Azizova TV, Geard CR, Burak LE, Mitchell CR, Khokhryakov VF, et al. Past exposure to densely ionizing radiation leaves a unique permanent signature in the genome. Am J Hum Genet. 2003;72:1162-70.

Jeggo PA, Geuting V, Löbrich M. The role of homologous recombination in radiation-induced double-strand break repair. Radiother Oncol. 2011;101:7-12.

Jostes RF, Bushnell KM, Dewey WC. X-Ray Induction of 8-Azaguanine-Resistant Mutants in Synchronous Chinese Hamster Ovary Cells. Radiat Res. 1980;83:146-61.
Kalikinskaya EI, Kolomiets OL, Shevchenko VA, Bogdanov YF. Chromosome aberrations in F1 from irradiated male mice studied by their synaptonemal complexes. Mutat Res. 1986; 174:59-65.

Kellerer AM, Hug O. Theory of dose-effect relations. In: Bauchinger M, Cronkite EP, Fliedner TM, Fritz-Niggli FH, Hug O, Kellerer AM, et al., editors. Strahlenbiologie / Radiation Biology: Teil 3 / Part 3. Berlin, Heidelberg: Springer Berlin Heidelberg; 1972. p. $1-42$.

Kellerer AM, Rossi HH. The theory of dual radiation action. Curr Top Radiat Res Q. 1972;8: 85-158.

King HO, Brend T, Payne HL, Wright A, Ward TA, Patel K, et al. RAD51 Is a Selective DNA Repair Target to Radiosensitize Glioma Stem Cells. Stem Cell Reports. 2017;8:125-39.

Klein CA, Schmidt-Kittler O, Schardt JA, Pantel K, Speicher MR, Riethmuller G. Comparative genomic hybridization, loss of heterozygosity, and DNA sequence analysis of single cells. Proc Natl Acad Sci USA. 1999;96:4494-9.

Kodaira M, Izumi S, Takahashi N, Nakamura N. No evidence of radiation effect on mutation rates at hypervariable minisatellite loci in the germ cells of atomic bomb survivors. Radiat Res. 2004;162:350-6.

Kodama K. Cytogenetic Study of the Offspring of Atomic Bomb Survivors, Hiroshima and $\mathrm{Na}$ gasaki. In: Neel JV, Schull WJ, editors. The Children of Atomic Bomb Survivors: A Genetic Study. Washington (DC): National Academies Press (US); 1991.

Korbel JO, Urban AE, Affourtit JP, Godwin B, Grubert F, Simons JF, et al. Paired-end mapping reveals extensive structural variation in the human genome. Science. 2007;318:4206.

Latt SA. Analysis of sister chromatid exchange and chromosome replication kinetics using Brd-U-dye techniques. Virchows Arch B Cell Pathol. 1978:29:19-27.

Lea DE. Actions of Radiations on Living Cells. London: Cambridge University Press; 1946.

Le Caignec C, Spits C, Sermon K, De Rycke M, Thienpont B, Debrock S, et al. Single-cell chromosomal imbalances detection by array CGH. Nucleic Acids Res. 2006;34:e68.

Lee W, Han K, Harris CP, Shim S, Kim S, Meisner LF. Use of FISH to detect chromosomal translocations and deletions. Analysis of chromosome rearrangement in synovial sarcoma cells from paraffin-embedded specimens. Am J Pathol. 1993;143:15-9.

Liber HL, Thilly WG. Mutation assay at the thymidine kinase locus in diploid human lymphoblasts. Mutat Res. 1982;94:467-85.

Liber HL, Yandell DW, Little JB. A comparison of mutation induction at the tk and hprt loci in human lymphoblastoid cells; quantitative differences are due to an additional class of mutations at the autosomal tk locus. Mutat Res. 1989;216:9-17

Liberi G, Foiani M. The double life of Holliday junctions. Cell Res. 2010;20:611-3. 
Lichter P, Cremer T, Borden J, Manuelidis L, Ward DC. Delineation of individual human chromosomes in metaphase and interphase cells by in situ suppression hybridization using recombinant DNA libraries. Hum Genet. 1988;80:224-34.

Lottersberger F, Karssemeijer RA, Dimitrova N, de Lange T. 53BP1 and the LINC Complex Promote Microtubule-Dependent DSB Mobility and DNA Repair. Cell. 2015;163:88093.

Loucas BD, Cornforth MN. Complex chromosome exchanges induced by gamma rays in human lymphocytes: an mFISH study. Radiat Res. 2001;155:660-71.

Loucas BD, Eberle R, Bailey SM, Cornforth MN. Influence of dose rate on the induction of simple and complex chromosome exchanges by gamma rays. Radiat Res. 2004;162:339-49.

Loucas BD, Durante M, Bailey SM, Cornforth MN. Chromosome damage in human cells by rays, particles and heavy ions: track interactions in basic dose-response relationships. Radiat Res. 2013;179:9-20.

Luxton JJ, McKenna MJ, Lewis A, Taylor LE, George KA, Dixit SM, et al. Telomere Length Dynamics and DNA Damage Responses Associated with Long-Duration Spaceflight. Cell Rep. 2020a;33:108457.

Luxton JJ, McKenna MJ, Taylor LE, George KA, Zwart SR, Crucian BE, et al. Temporal Telomere and DNA Damage Responses in the Space Radiation Environment. Cell Rep. 2020b;33:108435.

Mancini M, Nanni M, Cedrone M, Diverio D, Avvisati $G$, Riccioni $R$, et al. Combined cytogenetic, FISH and molecular analysis in acute promyelocytic leukaemia at diagnosis and in complete remission. Br J Haematol. 1995;91: 878-84.

McClintock B. Cytological observations of deficiencies involving known genes, translocations and an inversion in Zea mays. Columbia, Mo: University of Missouri, College of Agriculture, Agricultural Experiment Station; 1931.

McClintock B. The significance of responses of the genome to challenge. Science. 1984;226: 792-801.

McKenna MJ, Robinson E, Taylor L, Tompkins C, Cornforth MN, Simon SL, et al. Chromosome Translocations, Inversions and Telomere Length for Retrospective Biodosimetry on Exposed U.S. Atomic Veterans. Radiat Res. 2019;191:311-22.

Meselson M, Stahl FW. The Replication of DNA in Escherichia coli. Proc Natl Acad Sci USA. 1958;44:671.

Meyne J, Goodwin EH. Direction of DNA sequences within chromatids determined using strand-specific FISH. Chromosome Res. 1995;3:375-8

Mitchell JB, Bedford JS, Bailey SM. Dose-Rate Effects in Mammalian Cells in Culture: III. Comparison of Cell Killing and Cell Proliferation during Continuous Irradiation for Six Different Cell Lines. Radiat Res. 1979;79:537_ 51.
Mladenov E, Staudt C, Soni A, Murmann-Konda T, Siemann-Loekes M, Iliakis G. Strong suppression of gene conversion with increasing DNA double-strand break load delimited by 53BP1 and RAD52. Nucleic Acids Res. 2019; 48:1905.

Morris T, Thacker J. Formation of large deletions by illegitimate recombination in the HPRT gene of primary human fibroblasts. Proc Natl Acad Sci USA. 1993;90:1392-6.

Morris T, Masson W, Singleton B, Thacker J. Analysis of large deletions in the HPRT gene of primary human fibroblasts using the polymerase chain reaction. Somat Cell Mol Genet. 1993;19:9-19.

Muhlmann-Diaz MC, Bedford JS. Comparison of gamma-ray-induced chromosome ring and inversion frequencies. Radiat Res. 1995;143: $175-80$.

Muller HJ. Artificial Transmutation of the Gene. Science. 1927a;66(1699):84-7.

Muller HJ. Effects of X-radiation on genes and chromosomes: Read at the AAAS Conference in Nashville, Tennessee. Bloomington, IN: Lilly Library, Muller mss., Indiana University; 1927b.

Muller HJ. The production of mutations by Xrays. Proc Natl Acad Sci USA. 1928;14(9):714.

Nakamura N. Genetic effects of radiation in atomic-bomb survivors and their children: past, present and future. J Radiat Res. 2006; 47(Suppl B):B67-73.

Nakaseko Y, Adachi Y, Funahashi S, Niwa O, Yanagida M. Chromosome walking shows a highly homologous repetitive sequence present in all the centromere regions of fission yeast. EMBO J. 1986;5:1011-21.

Natarajan AT. Mechanisms for induction of mutations and chromosome alterations. Environ Health Perspect. 1993;101(Suppl 3):225-9.

Nauman CH, Underbrink AG, Sparrow AH. Influence of Radiation Dose Rate on Somatic Mutation Induction in Tradescantia Stamen Hairs. Radiat Res. 1975;62:79-96.

Neary GJ. Chromosome aberrations and the theory of RBE. 1. General considerations. Int J Radiat Biol Relat Stud Phys Chem Med. 1965a;9:477-502.

Neary GJ. The relation between the exponent of dose response for chromosome aberrations and the relative contribution of "two-track" and "one-track" processes. Mutat Res. 1965b; 2:242-6.

Neves H, Ramos C, da Silva MG, Parreira A, Parreira $\mathrm{L}$. The nuclear topography of $\mathrm{ABL}, \mathrm{BCR}$, $\mathrm{PML}$, and RARalpha genes: evidence for gene proximity in specific phases of the cell cycle and stages of hematopoietic differentiation. Blood. 1999;93:1197-207.

Nilsson D, Pettersson M, Gustavsson P, Förster A, Hofmeister W, Wincent J, et al. Whole-Genome Sequencing of Cytogenetically Balanced Chromosome Translocations Identifies Potentially Pathological Gene Disruptions and Highlights the Importance of Microhomology in the Mechanism of Formation. Hum Mutat. 2017;38:180-92.
Peng Y, Nagasawa H, Warner C, Bedford JS. Genetic susceptibility: radiation effects relevant to space travel. Health Phys. 2012;103:60720.

Perry P, Wolff S. New Giemsa method for the differential staining of sister chromatids. Nature. 1974;251:156-8.

Pinkel D, Straume T, Gray JW. Cytogenetic analysis using quantitative, high-sensitivity, fluorescence hybridization. Proc Natl Acad Sci USA. 1986;83:2934-8.

Plan Y, Hlatky L, Hahnfeldt P, Sachs R, Loucas B, Cornforth M. Full-color painting reveals an excess of radiation-induced dicentrics involving homologous chromosomes. Int J Radiat Biol. 2005;81:613-20.

Preston R, Au W, Bender M, Brewen J, Carrano A, Heddle J, et al. Mammalian in vivo and in vitro cytogenetic assays: A report of the U.S. EPA's Gene-Tox Program. Mutat Res. 1981; 87:143-88.

Putnam FW. The Atomic Bomb Casualty Commission in retrospect. Proc Natl Acad Sci USA. 1998;95:5426.

Quillardet P, Arrault X, Michel V, Touati E. Organ-targeted mutagenicity of nitrofurantoin in Big Blue transgenic mice. Mutagenesis. 2006;21:305-11.

Ray FA, Zimmerman E, Robinson B, Cornforth MN, Bedford JS, Goodwin EH, et al. Directional genomic hybridization for chromosomal inversion discovery and detection. Chromosome Res. 2013;21:165-74.

Ray FA, Robinson E, McKenna M, Hada M, George K, Cucinotta F, et al. Directional genomic hybridization: inversions as a potential biodosimeter for retrospective radiation exposure. Radiat Environ Biophys. 2014;53: 255-63.

Revell SH. Relationship between chromosome damage and cell death. In: Ishihara T, Sasaki MS, editors. Radiation-induced chromosome damage in man. New York: Liss; 1983. p. $215-$ 33.

Richardson C, Jasin M. Frequent chromosomal translocations induced by DNA doublestrand breaks. Nature. 2000a;405:697-700.

Richardson C, Jasin M. Recombination between two chromosomes: implications for genomic integrity in mammalian cells. Cold Spring Harb Symp Quant Biol. 2000b;65: 553-60.

Ritter S, Durante M. Heavy-ion induced chromosomal aberrations: A review. Mutat Res. 2010; 701: 38-46.http: //dx.doi.org/10.1016/js. mrgentox.2010.04.007

Robinson E, McKenna MJ, Bedford JS, Goodwin EH, Cornforth MN, Bailey SM, et al. Directional Genomic Hybridization ( $\mathrm{dGH}$ ) for Detection of Intrachromosomal Rearrangements. Methods Mol Biol. 2019;1984:10716.

Rothkamm K, Gunasekara K, Warda SA, Krempler A, Löbrich M. Radiation-Induced HPRT Mutations Resulting from Misrejoined DNA Double-Strand Breaks. Radiat Res. 2008;169: 639-48. 
Rowley JD. Molecular cytogenetics: Rosetta stone for understanding cancer--twenty-ninth G. $\mathrm{H}$. A. Clowes memorial award lecture. Cancer Res. 1990;50:3816-25.

Russell LB, Hunsicker PR. The Effect of Dose Rate on the Frequency of Specific-Locus Mutations Induced in Mouse Spermatogonia is Restricted to Larger Lesions; a Retrospective Analysis of Historical Data. Radiat Res. 2012; 177:555-64.

Russell WL. X-ray-induced mutations in mice. Cold Spring Harb Symp Quant Biol. 1951;16: 327-36.

Russell WL, Kelly EM. Mutation frequencies in male mice and the estimation of genetic hazards of radiation in men. Proc Natl Acad Sci USA. 1982;79:542-4.

Russell WL, Russell LB, Kelly EM. Radiation Dose Rate and Mutation Frequency. Science. 1958; 128:1546.

Sabatier L, Al Achkar W, Hoffschir F, Luccioni C, Dutrillaux B. Qualitative study of chromosomal lesions induced by neutrons and neon ions in human lymphocytes at G0 phase. Mutat Res. 1987;178:91-7.

Sadamoto S, Suzuki S, Kamiya K, Kominami R, Dohi K, Niwa O. Radiation induction of germline mutation at a hypervariable mouse minisatellite locus. Int J Radiat Biol. 1994;65: 549-57.

Savage JR. Classification and relationships of induced chromosomal structual changes. J Med Genet. 1976;13:103-22.

Savage JR. Assignment of aberration breakpoints in banded chromosomes. Nature. 1977;270: 513-4.

Savage JR. Cancer. Proximity matters.Science. 2000;290:62-3.

Sax K. An analysis of X-ray induced chromosomal aberrations in Tradescantia. Genetics. 1940;25(1):41-68.

Seabright M. A Rapid Banding Technique for $\mathrm{Hu}-$ man chromosomes. Lancet. 1971;298(7731): 971-2.

Searle AG. Mutation Induction in Mice. In: Lett $\mathrm{JT}$, Adler $\mathrm{H}$, Zelle $\mathrm{M}$, editors. Advances in Radiation Biology. Elsevier; 1974. p. 131-207.

Sedelnikova OA, Pilch DR, Redon C, Bonner WM. Histone H2AX in DNA damage and repair. Cancer Biol Ther. 2003;2:233-5.

Seol J-H, Shim EY, Lee SE. Microhomology-mediated end joining: Good, bad and ugly. Mutat Res. 2018;809:81-7.
Shibata A, Conrad S, Birraux J, Geuting V, Barton $\mathrm{O}$, Ismail A, et al. Factors determining DNA double-strand break repair pathway choice in G2 phase. EMBO J. 2011;30:1079-92.

Shigematsu I, Mendelsohn ML. The Radiation Effects Research Foundation of Hiroshima and Nagasaki: Past, Present, and Future. JAMA. 1995;274:425-6.

Shuryak I, Loucas BD, Cornforth MN. Robbing Peter to Pay Paul: Competition for Radiogenic Breaks During Rejoining Diminishes Curvature in the Dose Response for Simple Chromosome Exchanges. Radiat Res. 2021;196: $147-55$.

Simpson PJ, Savage JR. Dose-response curves for simple and complex chromosome aberrations induced by X-rays and detected using fluorescence in situ hybridization. Int J Radiat Biol. 1996;69:429-36.

Soni A, Murmann-Konda T, Siemann-Loekes M, Pantelias GE, Iliakis G. Chromosome breaks generated by low doses of ionizing radiation in G2-phase are processed exclusively by gene conversion. DNA Repair (Amst). 2020;89: 102828.

Speicher MR, Gwyn Ballard S, Ward DC. Karyotyping human chromosomes by combinatorial multi-fluor FISH. Nat Genet. 1996;12: 368-75.

Stadler LJ. Mutations in Barley Induced by XRays and Radium. Science. 1928;68:186-7.

Stadler LJ. The experimental modification of heredity in crop plants. 1. Induced chromosomal irregularities. Sci Agricult. 1931;11:557-72.

Stadler LJ. On the genetic nature of induced mutations in plants. Proceedings of the Sixth International Congress of Genetics; 1932.

Taylor JH. Sister Chromatid Exchanges in Tritium-Labeled Chromosomes. Genetics. 1958; 43:515-29.

Taylor JH, Woods PS, Hughes WL. The Organization and Duplication of Chromosomes as Revealed by Autoradiographic Studies Using Tritium-Labeled Thymidinee. Proc Natl Acad Sci USA. 1957;43:122-8.

Testard I, Dutrillaux B, Sabatier L. Chromosomal aberrations induced in human lymphocytes by high-LET irradiation. Int J Radiat Biol. 1997;72:423-33.
Thacker J, Cox R. The relationship between specific chromosome aberrations and radiationinduced mutations in cultured mammalian cells. In: Ishihara T, Sasaki MS, editors. Radiation-Induced Chromosome Damage in Man. New York: Alan Liss; 1983. p. 235-75.

Thacker J, Stretch A, Stephens MA. Th induction of thioguanine-resistant mutants of Chinese hamster cells by gamma-rays. Mutat Res. 1977;42:313-26.

Thacker J, Stephens MA, Stretch A. Mutation to ouabain-resistance in Chinese hamster cells: Induction by ethyl methanesulphonate and lack of induction by ionising radiation. Mutat Res. 1978;51:255-70.

Vergult S, Van Binsbergen E, Sante T, Nowak S, Vanakker O, Claes K, et al. Mate pair sequencing for the detection of chromosomal aberrations in patients with intellectual disability and congenital malformations. Eur J Hum Genet. 2014;22:652-9.

Waldren C, Jones C, Puck TT. Measurement of mutagenesis in mammalian cells. Proc Nat Acad Sci USA. 1979;76:1358-62.

Ward JF. The yield of DNA double-strand breaks produced intracellularly by ionizing radiation: a review. Int J Radiat Biol. 1990;57:114150.

Wells RL, Bedford JS. Dose-rate effects in mammalian cells. IV. Repairable and nonrepairable damage in noncycling C3H $10 \mathrm{~T} 1 / 2$ cells. Radiat Res. 1983;94:105-34.

Williams ES, Cornforth MN, Goodwin EH, Bailey $\mathrm{SM}$, et al. CO-FISH, COD-FISH, ReD-FISH, SKY-FISH. Methods Mol Biol. 2011;735:11324.

Wilson AB, Seilly D, Willers C, Vannais DB, McGraw M, Waldren CA, et al. Antigen S1, Encoded by the MIC1 Gene, is Characterized as an Epitope of Human CD59, Enabling Measurement of Mutagen-Induced Intragenic Deletions in the AL Cell System. Somat Cell Mol Genet. 1999;25:147-57.

Wolff S. The kinetics for two-break chromosome exchanges and the $3 / 2$ power rule. In: Sobels FH, editor. Repair from Genetic Radiation Damage and Differential Radiosensitivity in Germ Cells. New York: Pergamon Press; 1963. p. 1-10.

Wolff S. Genetic effects of ionizing radiation in multicellular eukaryotes and the assessment of genetic radiation hazards in man. Am J Hum Genet. 1983;35:324-5. 